\title{
The rare injury of a closed digital extensor tendon avulsion of the third finger at its musculotendinous junction: Case presentation and brief overview of literature with regard to general, specific and practicable aspects to extensor tendon surgery involving tendon transfer procedures
}

\author{
Ingo Schmidt $^{1 *}$, Ivo Nennstiel ${ }^{2}$, Mkrtich Muradyan ${ }^{3}$, Andrea Schmieder ${ }^{4}$, Aristotelis Kaisidis ${ }^{5}$ and Dietrich Großmann ${ }^{6}$ \\ ${ }^{1}$ SRH Poliklinik Gera GmbH, Straße des Friedens 122, 07548 Gera, Germany \\ ${ }^{2}$ Ivo Nennstiel, SRH Zentralklinikum Suhl, Albert-Schweitzer-Str. 2, 98527 Suhl, Germany \\ ${ }^{3}$ Mkrtich Muradyan, Robert-Koch-Krankenhaus Apolda, Jenaer Str. 66, 99510 Apolda, Germany \\ ${ }^{4}$ Andrea Schmieder, Orthopädische Praxis (MVZ) Klinikum Burgenlandkreis GmbH, Humboldtstr. 31, 06618 Naumburg, Germany \\ ${ }^{5}$ Aristotelis Kaisidis, Frankfurter Rotkreuz-Kliniken eV, Scheffelstr. 2-14, 60318 Frankfurt/M, Germany \\ ${ }^{6}$ Dietrich Großmann, Poliklinik Eisenach (St. Georg Klinikum Eisenach), Mühlhäuser Str. 94, 99817 Eisenach, Germany
}

\begin{abstract}
Abbreviations: MCPJ: metacarpophalangeal joint; PIPJ: proximal interphalangeal joint; DIPJ: distal interphalangeal joint; MTJ: musculotendinous junction; TTP: tendon transfer procedure; EIP: extensor indicis proprius; EDC: extensor digitorum communis; MTU: muscletendon unit; TTP: tendon transfer procedure; PL: palmaris longus; IPJ: interphalangeal joint; FDC: flexor digitorum communis; EPL: extensor pollicis longus
\end{abstract}

\section{Case presentation}

A 29-year-old male sustained an occupational closed blunt trauma at the dorsal aspect in the middle third of his left forearm by a push on a metal rack of a machine that led to an active extension insufficiency of the 3rd finger. The injury was initially misdiagnosed as having an incomplete radial nerve palsy by another surgeon as well as his family doctor. On clinical examination in our hospital 6 weeks after injury, there was a visible and palpable non-tender mass at the dorsal aspect in the middle third of his left forearm with active strain of his left digital extensor muscles. The $3 \mathrm{rd}$ finger could not be active extended completely in its metacarpophalangeal joint (MCPJ) whereas the intrinsic-related active extension in its proximal interphalangeal joint (PIPJ) was not altered, and the active extension in its distal interphalangeal joint (DIPJ) was intact as well (Figure 1). However, there was not a complete finger drop that suggested that the isolated closed extensor tendon injury must have taken place proximal from the intertendinous connexions to adjacent index and/or 4th finger, that was confirmed intraoperatively (Figure 2A). Ultrasound revealed an avulsion injury at the musculotendinous junction (MTJ) of the left 3rd finger, and surgical revision by a tendon transfer procedure (TTP) utilizing the extensor indicis proprius (EIP) of the same hand was indicated and performed by us. Intraoperatively, the closed MTJ avulsion injury of the extensor digitorum communis (EDC) III was confirmed indirectly by pronounced passive elongation of the EDC III distal of its MTJ (Figure 2A). The EIP was detached distally, translocated, and sutured at the EDC III end-to-side using the 4-weave
Pulvertaft technique which provides early avtive motion (Figures 2BD). Postoperatively, the finger was not immobilized by static or dynamic splinting, and strengthening was started 6 weeks after surgery. Twelve weeks after surgery, the patient was functional recovered completely without an extension lag at the donor site (i.e. MCPJ II), and he was able to move his 3rd finger separately (Figure 3).

Closed subcutaneous extrinsic wrist and digital tendon ruptures caused by rheumatoid arthritis, crystal deposition diseases, attrition by internal hardware, distal radius fracture, or osteoarthritis at the Verdan's zones 1 to 7 are common. Regardless of open injuries, the weakest parts of the muscle-tendon unit (MTU) are the MTJ (i.e. Verdan's zone 8) and the bony insertion (i.e. Verdan's zone 1) [2]. Avulsions from distal bony insertion, such as the "jersey finger" for deep flexor tendon avulsion or the "mallet finger" for extensor tendon avulsion, are common and have been studied extensively. But avulsions from the MTJs are rare injuries except in avulsion amputations, and it has been observed in cases with combined open fractures of the fingers distally of the MTJ due to an injury when a work glove is caught in a machine, due to closed sports injuries arising from patients participating in gymnastics, judo, and baseball pitching exercises, as well as due to closed minor injuries such as taking the hand out of the trousers pocket or carrying a shopping bag in the absence of any risk factors [3-6]. First experimental works by McMaster in 1933 demonstrated that a closed MTJ avulsion can occur either from direct

Correspondence to: Ingo Schmidt, SRH Poliklinik Gera GmbH, Straße des Friedens 122, 07548 Gera, Germany, Tel: 00491789503035; E-mail: schmidtingo62@ googlemail.com

Key words: Forearm; Blunt trauma; Musculotendinous junction; Extensor digitorum communis avulsion injury; Tendon transfer procedure; Extensor indicis proprius transfer

Received: October 06, 2017; Accepted: October 17, 2017; Published: October 20,2017 
Schmidt I (2017) The rare injury of a closed digital extensor tendon avulsion of the third finger at its musculotendinous junction: Case presentation and brief overview of literature with regard to general, specific and practicable aspects to extensor tendon surgery involving tendon transfer procedures

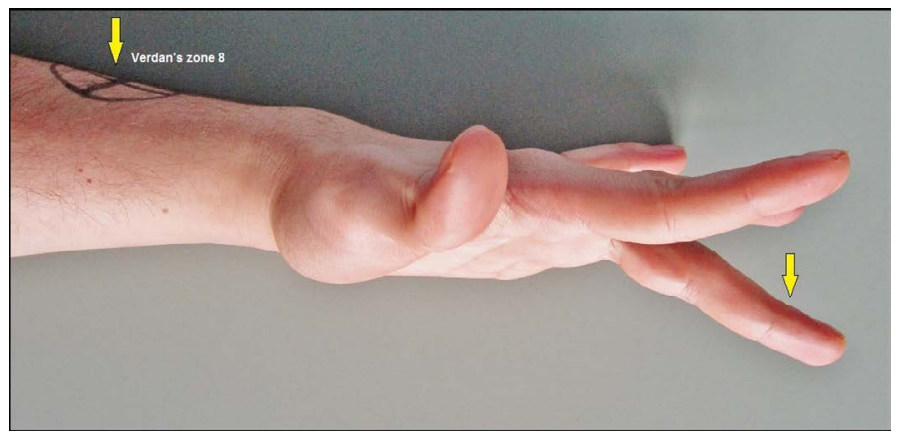

Figure 1 (Case presentation, initial findings): Clinical photograph showing that the patient was unable to extend his 3rd finger completely in its MCPJ whereas extension in PIPJ and DIPJ was not altered (arrow). The closed avulsion injury of the EDC III at its MTJ (i.e. Verdan's zone 8) was confirmed by ultrasound (arrow). Note that there was not a complete 3rd finger drop.

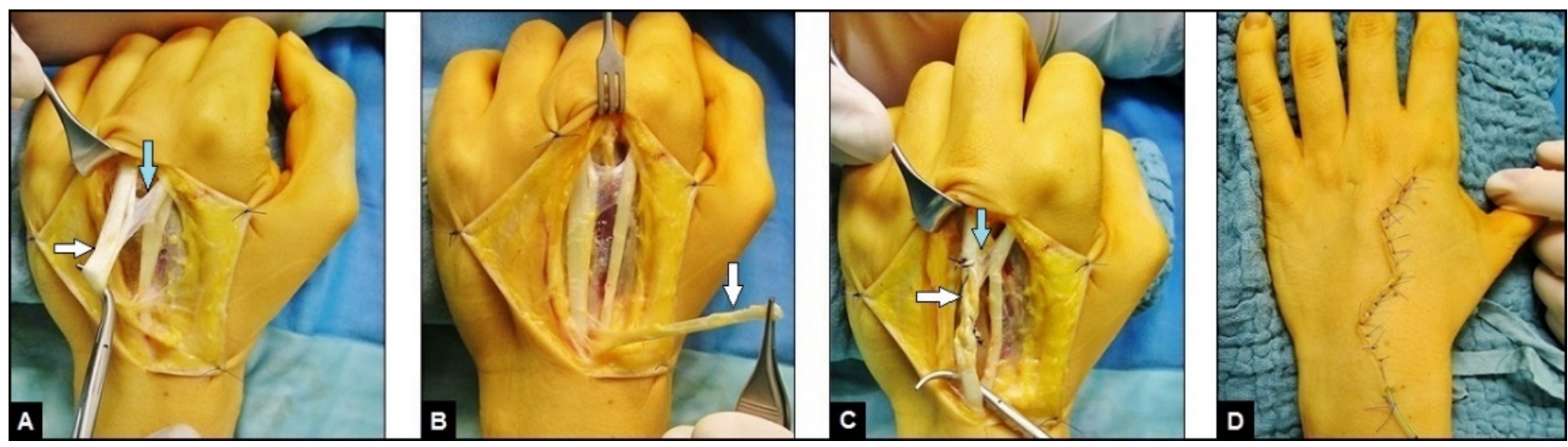

Figure 2 (Case presentation, intraoperative): (A) Clinical photograph demonstrating pronounced passive elongation of the EDC III tendon distal of its MTJ (white arrow) and confirmed indirectly the diagnosis of a closed avulsion injury at its MTJ. Note that the intertendinous connection II/III was not injured (blue arrow). (B) Clinical photograph showing the detached EIP tendon (arrow) at the MCPJ II. (C) Clinical photograph showing surgical repair by translocation of the detached EIP tendon to the EDC III tendon, the tendon suture was performed end-toside with the Pulvertaft 4-weave technique (white arrow), note that the intertendinous connection II/III is obtained (blue arrow). (D) Clinical photograph showing primary closure of surgical approach via Bruner's incision first described by him in 1973 [1].

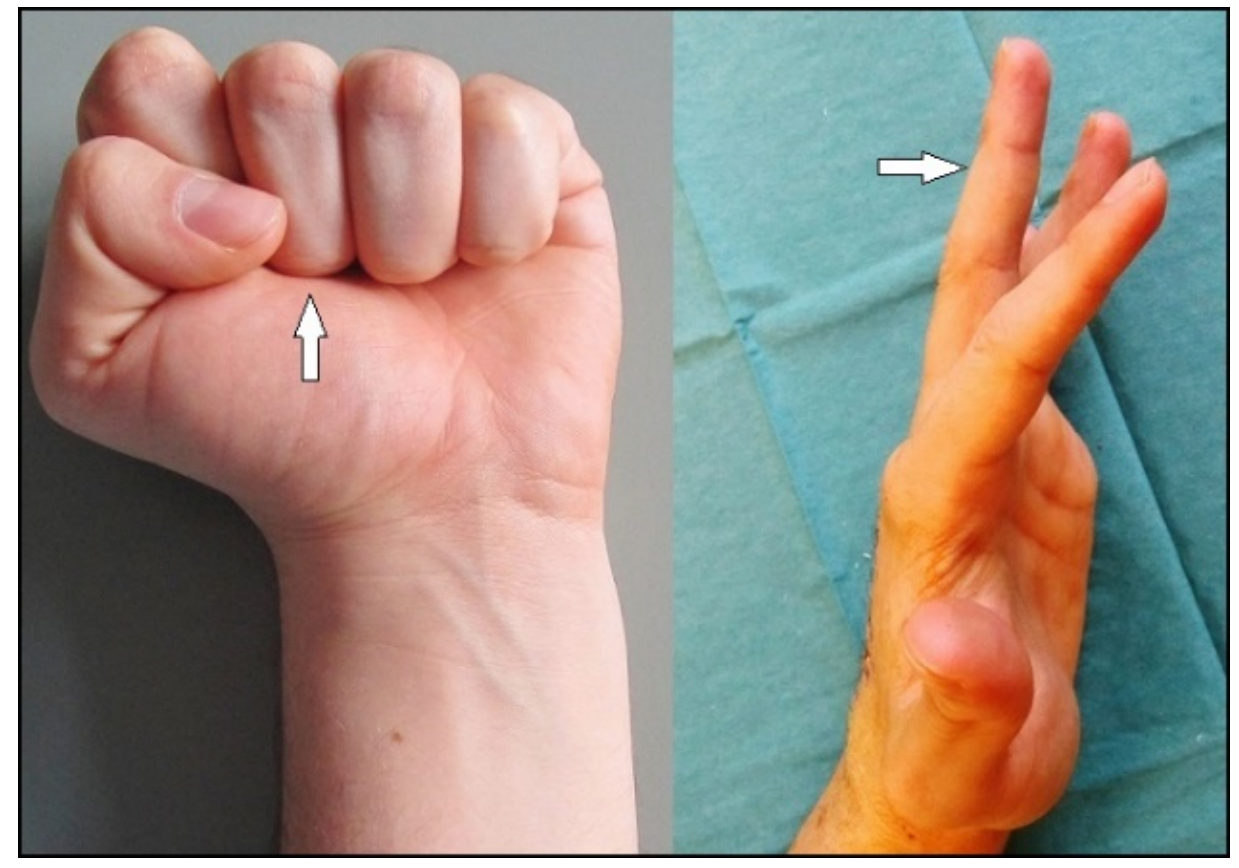

Figure 3 (Case presentation, postoperative course): Clinical photographs 12 weeks after surgery demonstrating complete functional recovery. Fist conclusion is uneventful with the correct aligned 3rd finger (arrow). The patient is able able to move (i.e. active extension) his 3rd finger separately (arrow) 
Schmidt I (2017) The rare injury of a closed digital extensor tendon avulsion of the third finger at its musculotendinous junction: Case presentation and brief overview of literature with regard to general, specific and practicable aspects to extensor tendon surgery involving tendon transfer procedures

trauma in which the tendon is compressed between the bone and an outside force, or from the more common indirect trauma in which the entire MTU is subjected to a longitudinal powerful passive traction in the opposite direction of muscle contraction [7]. With regards to the mechanism of injury, avulsion amputations with a relative portion of $62.6 \%$ are more common than closed avulsion injuries with a relative portion of $37.4 \%$, cases are mostly observed in males with a relative portion of $90,2 \%$ and a patient's mean age of 31 years (+/- 4), work injuries with a relative portion of $72.6 \%$ are more common than nonwork-related trauma and sports injuries with equal relative portions of $13.7 \%$, and avulsions of the extrinsic extensor tendons with a relative portion of $53.9 \%$ mainly affecting the extensor pollicis longus with $24.2 \%$ and followed by the extensor digitorum communis with $18.7 \%$ are slightly more frequent than avulsions of the extrinsic flexor tendons with a relative portion of $46,1 \%$ mainly affecting the flexor pollicis longus with $28.6 \%$ [4]. Due to the unfamiliarity of closed MTJ injuries by treating physicians, the lesion can be misdiagnosed initially such as in our presented case.

If an open or closed extrinsic digital extensor tendon injury is present, then there is no alternative to its surgical repair for preservation of motion in the MCPJs II-V in particular in cases when arthrodeses both in the PIPJ and DIPJ of the same long finger become necessary (Figures 4A-D). Furthermore, a stable and functioning MCPJ is the key for satisfactory function of the overall finger, hence, the preservation of its motion has a top priority [8,9]. The stable active extrinsic motionarc modulates synergistically the intrinsic function in the PIPJ for a powerful extension and fist conclusion. On the other hand, the actions of the intrinsic muscles are necessary for stabilizing the MCPJ in flexion posture during PIPJ motion. Functional flexion postures averaged about $60^{\circ}$ at the MCPJ and PIPJ, and $40^{\circ}$ at the DIPJ [10,11]. Also noted that a well functioning and exactly aligned extrinsic extensor mechanism is an essential prerequisite for success of total joint replacements in the wrist and all other long finger joints (Figures 5A-C, 6A-H, and 7A-D) $[8,9,12]$. When an intratendinous disruption of an extrinsic extensor tendon is accompanied with a large gap, the bridging of gap utilizing a free tendon graft such as the palmaris longus (PL) is the method of choice for surgical repair (Figures 8A-D). Generally, a stable and well vascularized soft tissue which surrounds the bradytrophe tendon tissue in the hand and foot is absolutely required for its nutrition via diffusion and sufficient gliding (i.e. avoiding of adhesion formation with the skin or ingrowth of granulation tissue when the synovial sheath is damaged) in particular when the extrinsic blood supply via the paratenon and/or synovial sheath is damaged such as in posttraumatic conditions with or without infection (Figures 9A-F, 10A-D, and 11A-E), postoperative complications (Figures 12A-E), or also after required large soft tissue excision in case of a malignancy [13-20]. Furthermore, early active motion without limitations after tendon repair in the hand by a stable tendon suture seems to be more favorable to prevent adhesion-related contractures and results in better functional outcomes than in patients who must treated by static or dynamic splinting postoperatively when a lesser stable tendon suture does not allow early active motion [2124]. Likewise, obtaining the centralizing and strengthen pulleys as well as the extensor retinaculum for the flexor and extensor tendons of the hand must always be aimed to avoid bowstring leading to functional loss and potentially resulting in contractures (Figures 12A-E and 13). Additionally, the well functioning ulnar-sided extrinsic extensor tendons are one of the most important stabilizing mechanism for the ulnar head especially when an ulnar head replacement with or without replacement of the sigmoid notch becomes necessary (i.e. avoiding subluxation and/or polyethylene wear) (Figures 14A-D and 15A-D). When a tendon repair or a TTP both in hand or foot is technically no longer possible, then the primary or secondary joint arthrodesis with or without correction of misalignment becomes necessary (Figures 16A-C and $17 \mathrm{~A}-\mathrm{C})[14,25,26]$.
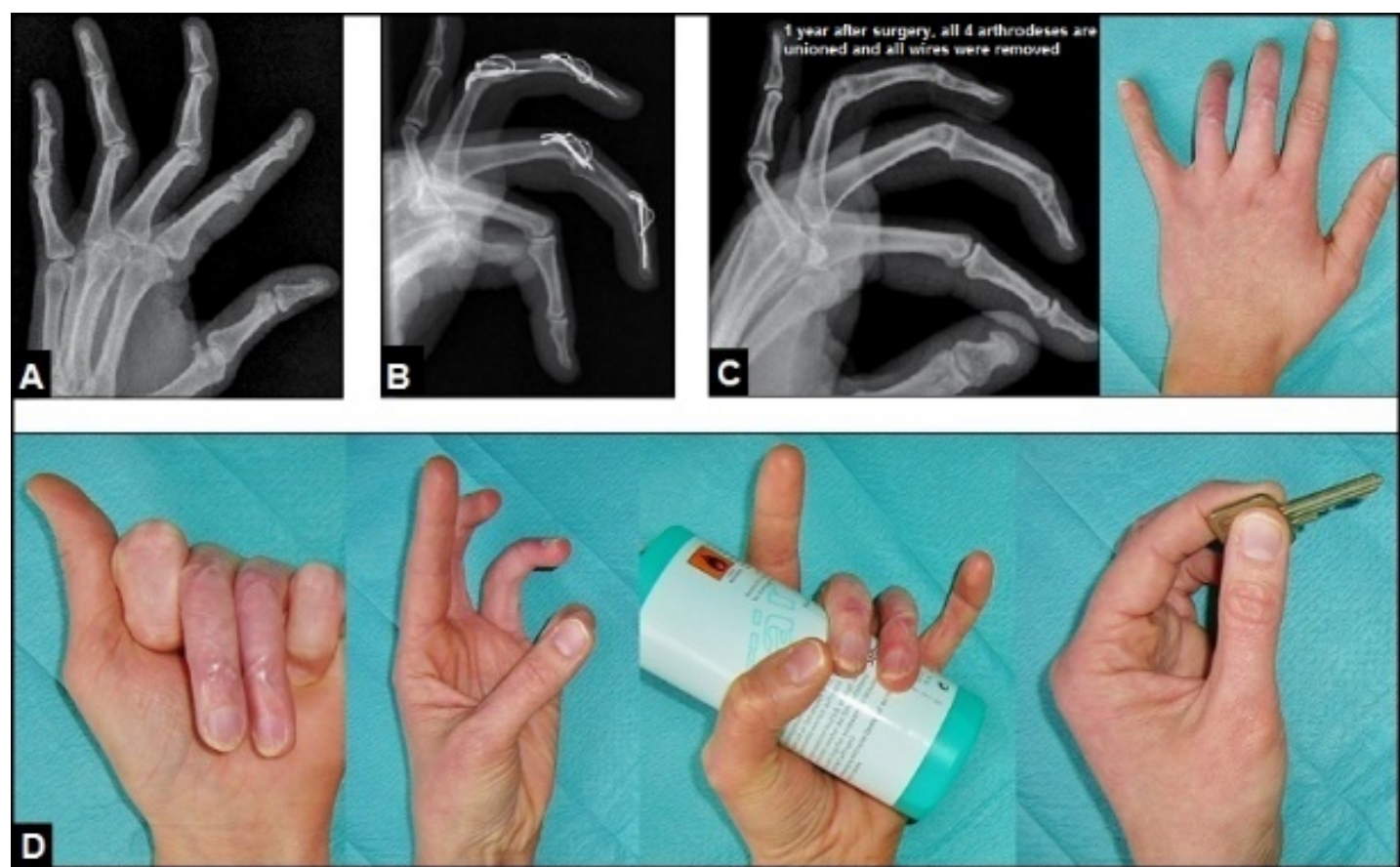

Figure 4 (Example for the necessity of preservation of function in MCPJ when arthrodeses in PIPJ and DIPJ of the same finger become necessary, 43-year-old female, left hand): (A) Initial radiograph showing posttraumatic passive fixed swan neck deformities of the 3rd and 4th finger. (B) Same patient, surgical treated by arthrodeses with its re-alignment in flexion position to provide a sufficient object grasp. (C) Same patient 1 year later, all arthrodeses were uneventful unioned that allowed removal of all wires. (D) Same patient, satisfactory functional recovery at the 1 -year follow-up. 
Schmidt I (2017) The rare injury of a closed digital extensor tendon avulsion of the third finger at its musculotendinous junction: Case presentation and brief overview of literature with regard to general, specific and practicable aspects to extensor tendon surgery involving tendon transfer procedures
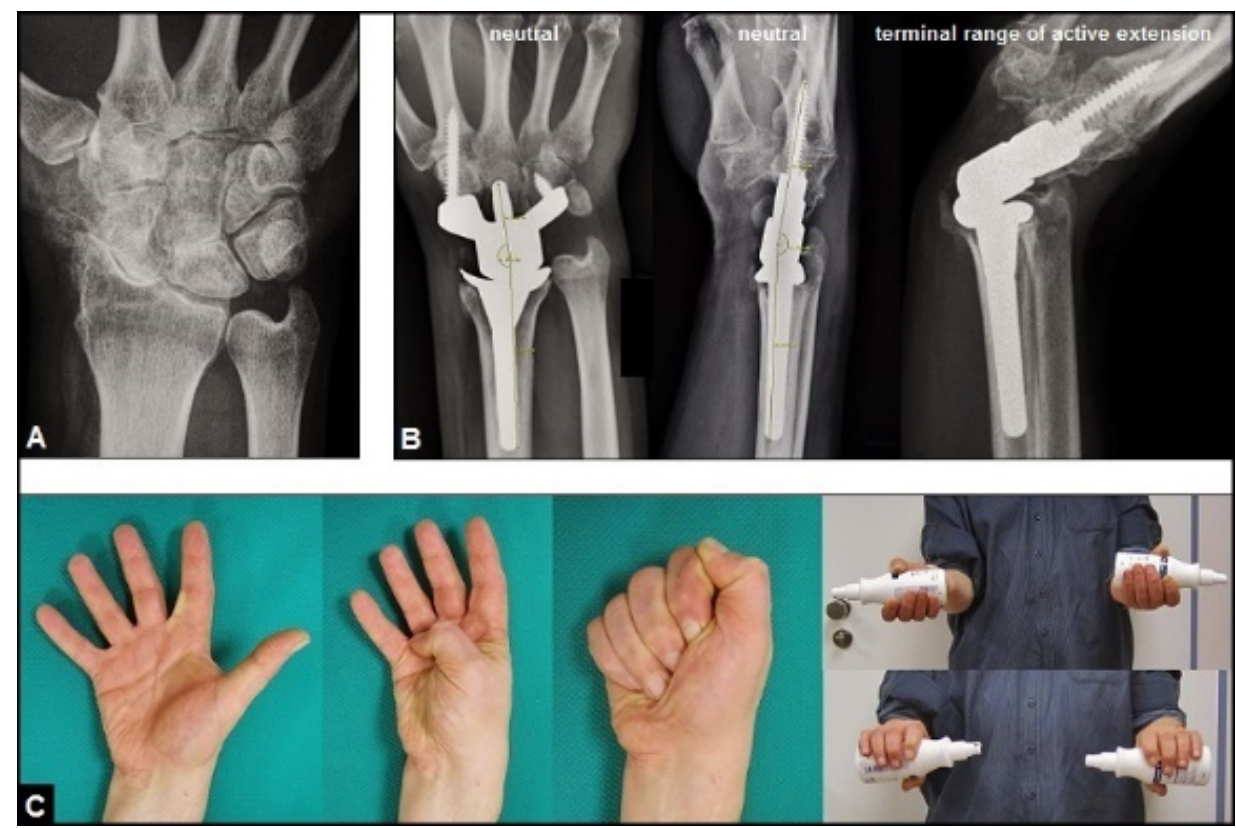

Figure 5 (Example for the necessity of well functioning and exactly aligned extrinsic extensor mechanism for success of a total wrist arthroplasty, 56-year-old male, right wrist): (A) Initial radiograph showing advanced stage of primary idiopathic osteoarthritis. (B) Same patient, treated by uncemented total wrist arthroplasty using the relatively new angle-stable Maestro $^{\mathrm{TM}}$ Wrist Reconstructive System (Biomet, Warsaw, Indiana/USA), note the stability of implant at terminal range of active extension. (C) Same patient, excellent functional outcome at the 5-year follow-up.
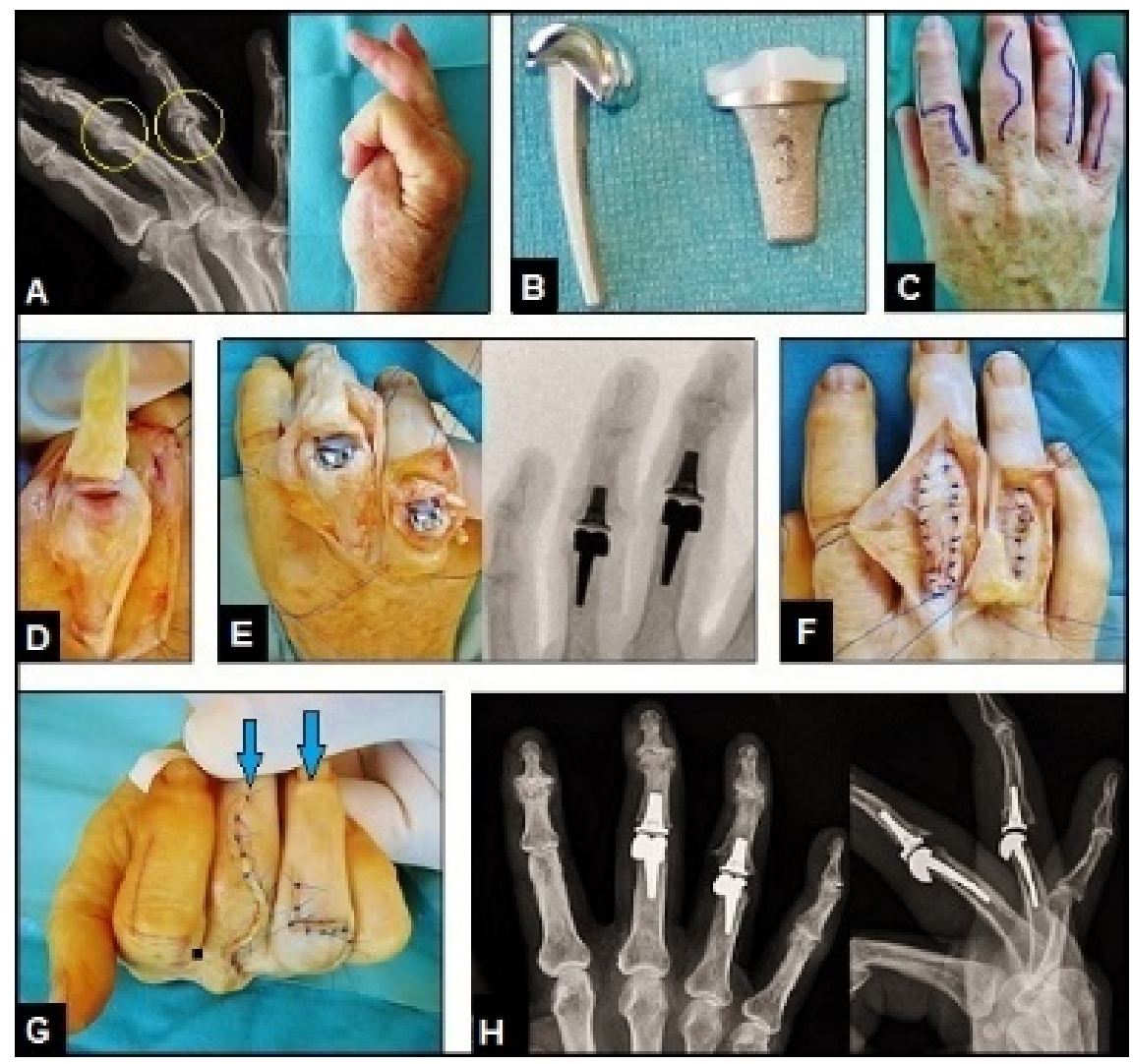

Figure 6 (Example for the necessity of well functioning and exactly aligned extrinsic extensor mechanism for success of PIPJ arthroplasties, 58-year-old male, right hand): (A) Initial radiograph showing advanced stage of polyarthritis mostly affecting the PIPJs of the 3rd and 4th finger (arrows) that led to marked loss of its functions. (B) Design of the uncemented resurfacing SR-PIP ${ }^{\mathrm{TM}}$ implant (Stryker Corporation, Kalamazoo, Michigan/USA) that was used for the patient. (C) Same patient, various options for dorsal surgical skin incisions to expose the PIPJs. (D) Same patient, the PIPJ of the 3rd finger was exposed by the Chamay technique in which the triangular incised extensor apparatus is broad-based pedicled distally at the base of the middle phalanx [27].(E) Same patient, treated by resurfacing PIPJ arthroplasties using the SR-PIP ${ }^{\mathrm{TM}}$ implants. (F) Same patient, closure of the extensor apparatus after insertion of the implants, note that the PIPJ of the 4th finger was exposed through a longitudinal incision of the extensor apparatus. (G) Same patient, correct alignment of the 3rd and 4th finger (arrows) after closure of wounds. (H) Same patient, correct alignment of the implants radiographically. 
Schmidt I (2017) The rare injury of a closed digital extensor tendon avulsion of the third finger at its musculotendinous junction: Case presentation and brief overview of literature with regard to general, specific and practicable aspects to extensor tendon surgery involving tendon transfer procedures

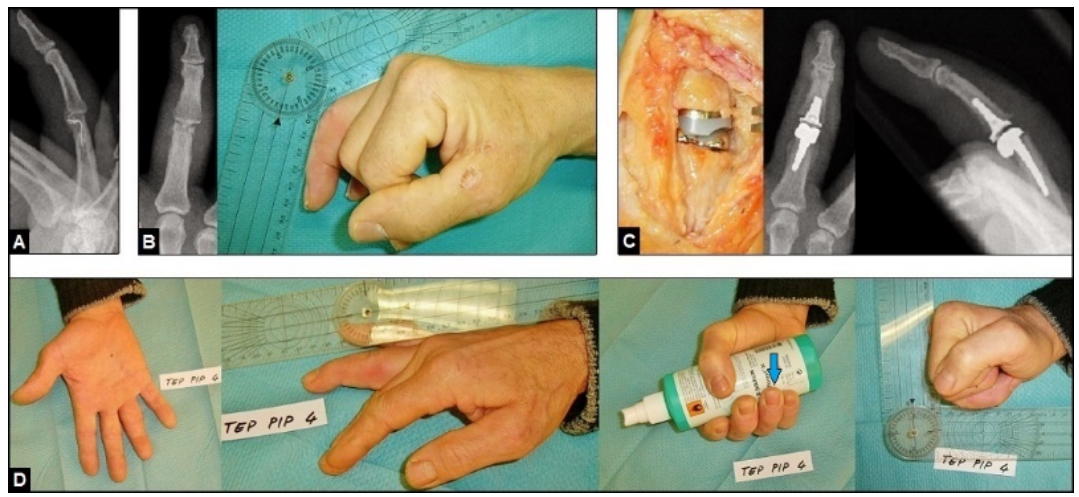

Figure 7 (Example for the necessity of well functioning and exactly aligned extrinsic extensor mechanism for success of PIPJ arthroplasty, 46-year-old male, right hand): (A) PIPJ empyema 4th finger due to a wooden splinter injury, initially treated by debridement and incorporation of polymethyl methacrylate beads containing gentamycin. (B) Same patient, the resulting postinfectous osteoarthritis led to a marked PIPJ ankylosis. (C) Same patient, insertion of the uncemented resurfacing SR-PIP ${ }^{\mathrm{TM}}$ implant with correct alignment. (D) Same patient, excellent functional outcome with the correctly aligned 4 th finger (arrow).

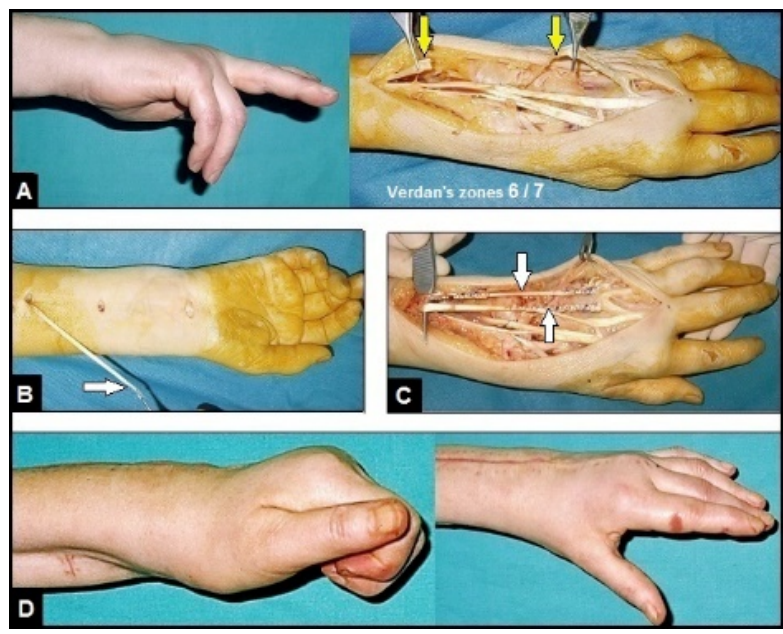

Figure 8 (Example for the necessity of gap bridging with the PL tendon in case of closed non-traumatic extrinsic digital extensor tendon disruptions, 65-year-old female suffered from rheumatoid arthritis, left hand): (A) Initial finding, complete loss of active extension in the MCPJs of the 4th and 5th finger (i.e. finger drops) due to intratendinous extensor tendon disruptions of both fingers associated with large gaps involving the wrist and distal part of forearm (arrows). (B) Same patient, dissection of the PL tendon for free transplantation (arrow). (C) Same patient, surgical repair with interposition of the PL tendon (arrows), the tendon sutures were done in the Pulvertaft 4-weave technique that allows early action motion without the necessity of static or dynamic splinting postoperatively. (D) Same patient, complete functional recovery 3 months after surgery.

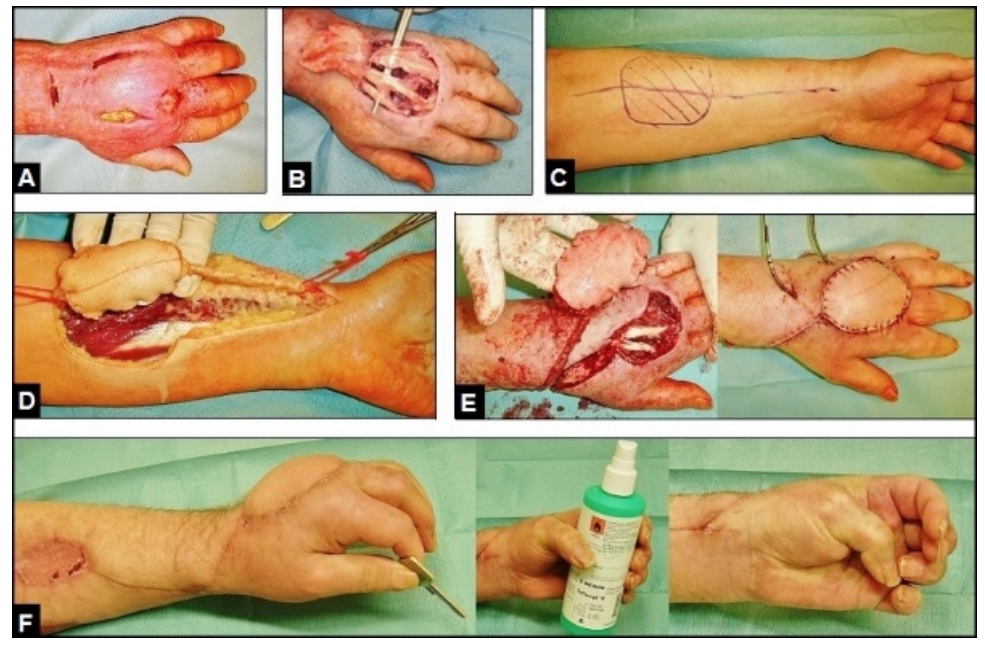

Figure 9 (Example for the necessity of coverage of the extrinsic digital extensor tendons in a postinfectious condition after a cat bite injury, 57 -year-old male, left hand): (A) The acute infection was primarily treated by surgical incisions and subcutaneous debridement. (B) Same patient, the infection led to progressive skin necrosis accompanied with pronounced functional loss due to severe adhesions of the extrinsic digital extensor tendons to the surrounding necrotic soft tissue that required surgical tenolyses accompanied with radical soft tissue debridement and coverage to restore its nutrition and stable gliding mechanism. (C) Same patient, planning of the distally pedicled radial artery flap for coverage [16, 28-32]. (D) Same patient, dissection of the flap with the use of a torniquet. (E) Same patient, transposition of the flap after release of torniquet and extended tenolyses, the donor site was primarily covered by free split-thickness skin grafts. (F) Same patient, satisfactory functional outcome 3 months after tenolyses and coverage. 
Schmidt I (2017) The rare injury of a closed digital extensor tendon avulsion of the third finger at its musculotendinous junction: Case presentation and brief overview of literature with regard to general, specific and practicable aspects to extensor tendon surgery involving tendon transfer procedures

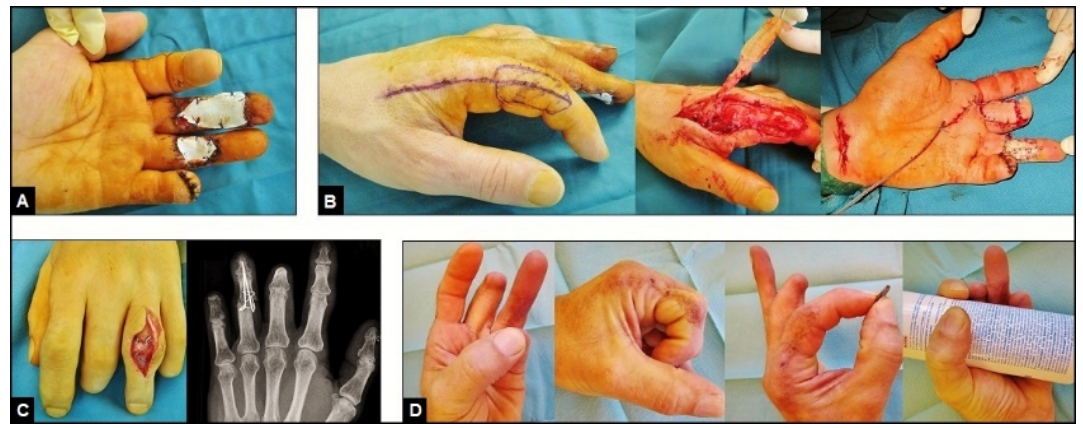

Figure 10 (Example for the necessity of coverage of the extrinsic digital flexor tendon in a traumatic condition after a circle saw injury, 43-year-old male, left hand): (A) The exposed flexor tendons at the proximal phalanges of the 3rd and 4th finger were primarily covered with a synthetic skin substitute. (B) Same patient, planning, dissection and transposition of a by Foucher and Braun modified Hilgenfeldt's first dorsal metacarpal artery skin island flap [33, 34] for coverage of the exposed superficial flexor tendon of the 3rd finger, the donor site of flap was primarily covered by a free skin transplant. Note that a secondary amputation of the same finger at the proximal level of the middle phalanx had to be performed due to progressive posttraumatic ischemia. The primarily exposed flexor tendons of the 4th finger were covered by free skin transplants. (C) Same patient, secondary arthrodeses of the PIPJ an DIPJ of the 4th finger were necessary. (D) Same patient, satisfactory functional outcome 3 months after injury, the reconstructed stable soft tissue provides sufficient gliding of the primarily exposed flexor tendons.
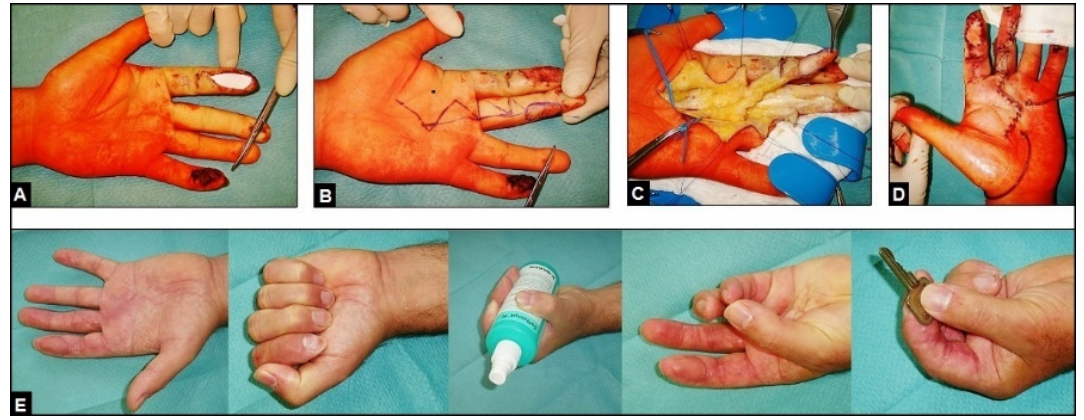

Figure 11 (Example for the necessity of coverage of the extrinsic digital flexor tendon in a traumatic condition after a circle saw injury, 45-year-old male, left hand): (A) The exposed deep flexor tendon at the distal part of middle phalanx of the index was primarily covered by a synthetic skin substitute. (B) Same patient, planning of the Littler's neurovascular skin island transposition flap [35] from the ulnar site of the 3rd finger for coverage. (C) Same patient, dissection of the Littler's flap. (D) Same patient, transposition of the Littler's flap to the index, the donor site of the 3rd finger was primarily covered by a free skin transplant. (E) Same patient, excellent functional outcome 3 months after injury, the reconstructed stable soft tissue provides sufficient gliding of the primarily exposed deep flexor tendon of the index.
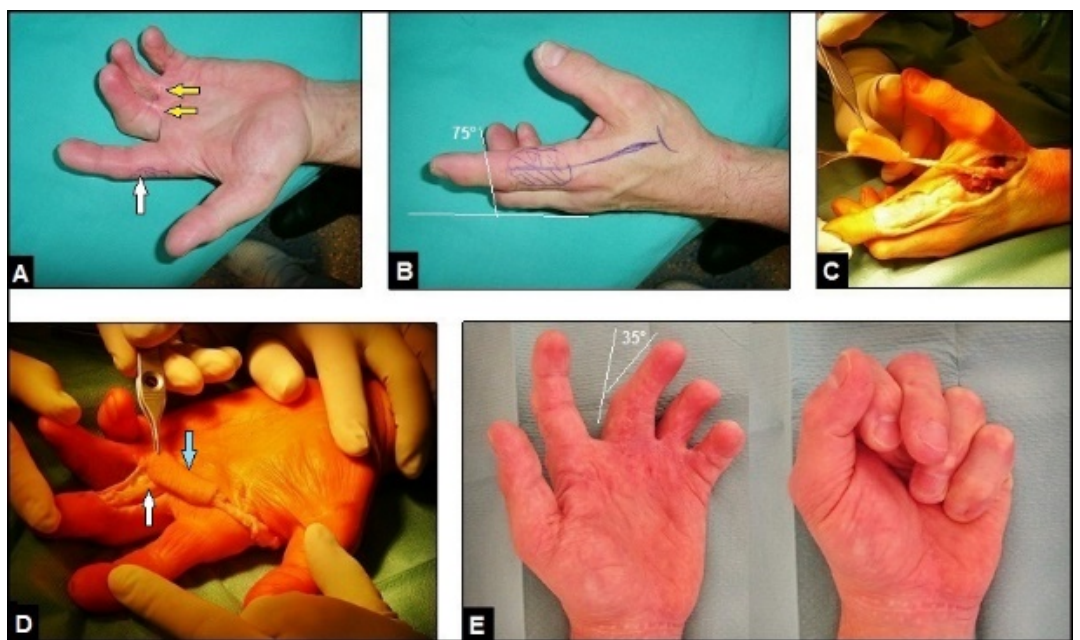

Figure 12 (Example for the necessity of coverage of the extrinsic digital flexor tendon in a longstanding postoperative complicated condition after A1 pulley releases, 51-year-old male, left hand): (A) Initial findings, during the surgical releases of the A1 pulleys of the 3rd and 4th finger several years previously in another hospital there were probably iatrogenic injuries of the A2 pulleys of both fingers that led to bowstring and resulted in flexion contractures in the PIPJs of both fingers due to adhesions of the flexor tendons to the skin (yellow arrows). Note that the adjacent non-operated index is not involved in flexion contracture (white arrow) which is a very important differential diagnosis to the "clenched fist syndrome" (first described in by Simmons and Vasile in 1980) after minor trauma or surgery such as pulley releases or revision of a peripheral nerve compression syndrome in which the adjacent nonoperated or non-injured fingers are generally involved in contractures and often presented as an intrinsic-plus hand with flexion contracture in the MCPJ whereas the PIPJ is not involved in flexion contracture and a preexistent psychiatric disorder is common with these patients [36-46]. (B) Same patient, planning the first dorsal metacarpal artery skin island flap such as in Figures 10A-D for coverage of the flexor tendons at the level of proximal phalanx of the 3rd finger accompanied with tenolysis and A2 pulley repair. (C) Same patient, dissection of the flap. (D) Same patient, transposition of the flap (blue arrow), note the pre-existent iatrogenic A2 pulley injury (white arrow). (E) Same patient, 6 months after A2 pulley repair and coverage the function in PIPJ of the 3rd finger had marked improved, the reconstructed stable soft tissue provides sufficient gliding of both flexor tendons. 
Schmidt I (2017) The rare injury of a closed digital extensor tendon avulsion of the third finger at its musculotendinous junction: Case presentation and brief overview of literature with regard to general, specific and practicable aspects to extensor tendon surgery involving tendon transfer procedures

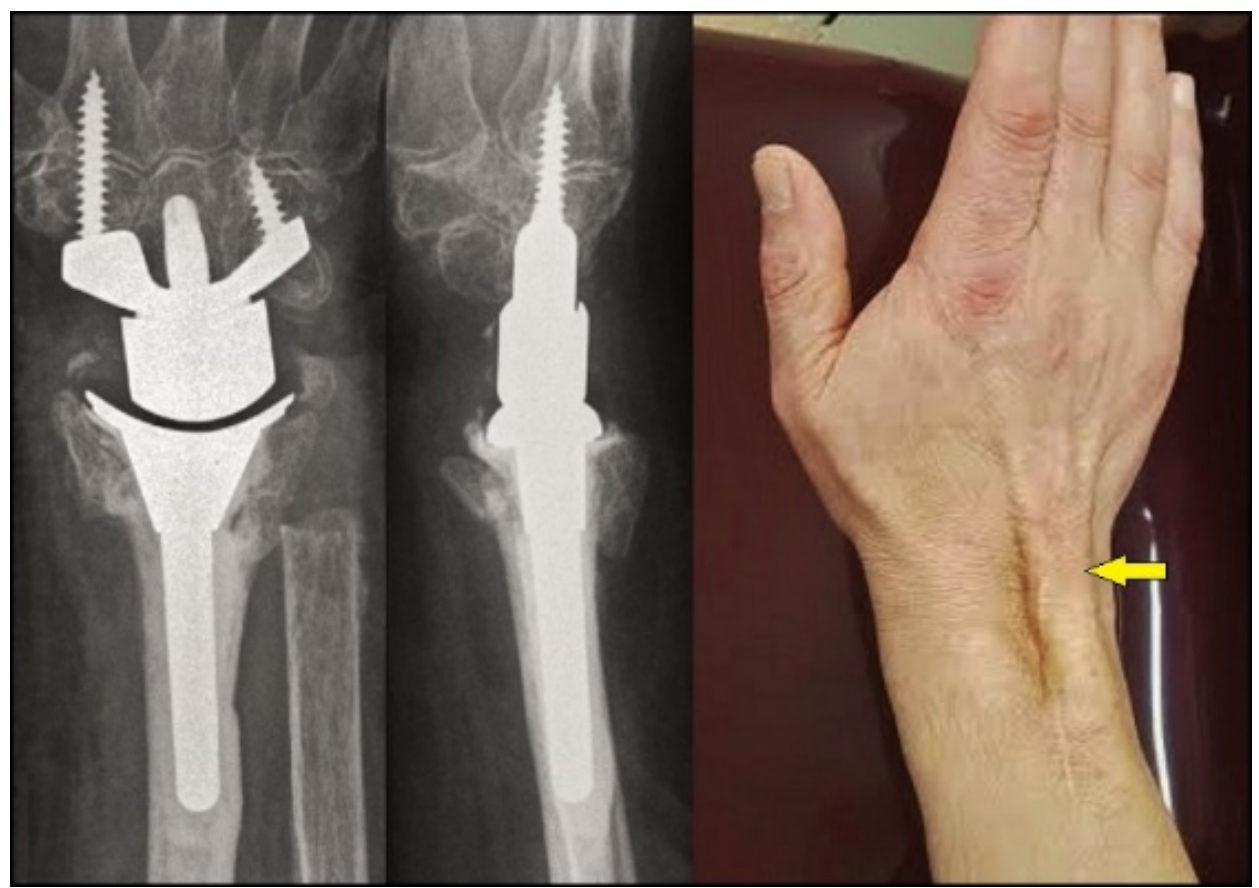

Figure 13 (Example for dorsal bowstring due to disruption of the extensor retinaculum, 86-year-old female, right wrist): This patient sustained a primary partially cemented total wrist arthroplasty with the same implant as in Figures 5A-C accompanied with an ulnar head resection in case of a highly comminuted distal radius fracture. The dorsal retinaculum was reconstructed intraoperatively such as recommended generally [47]. However, it has disrupted again 2 years after surgery and led to bowstring of the EDC tendons (arrow) associated with a loss of active extension of $10^{\circ}$ in comparison to the state before its subcutaneous disruption [48]
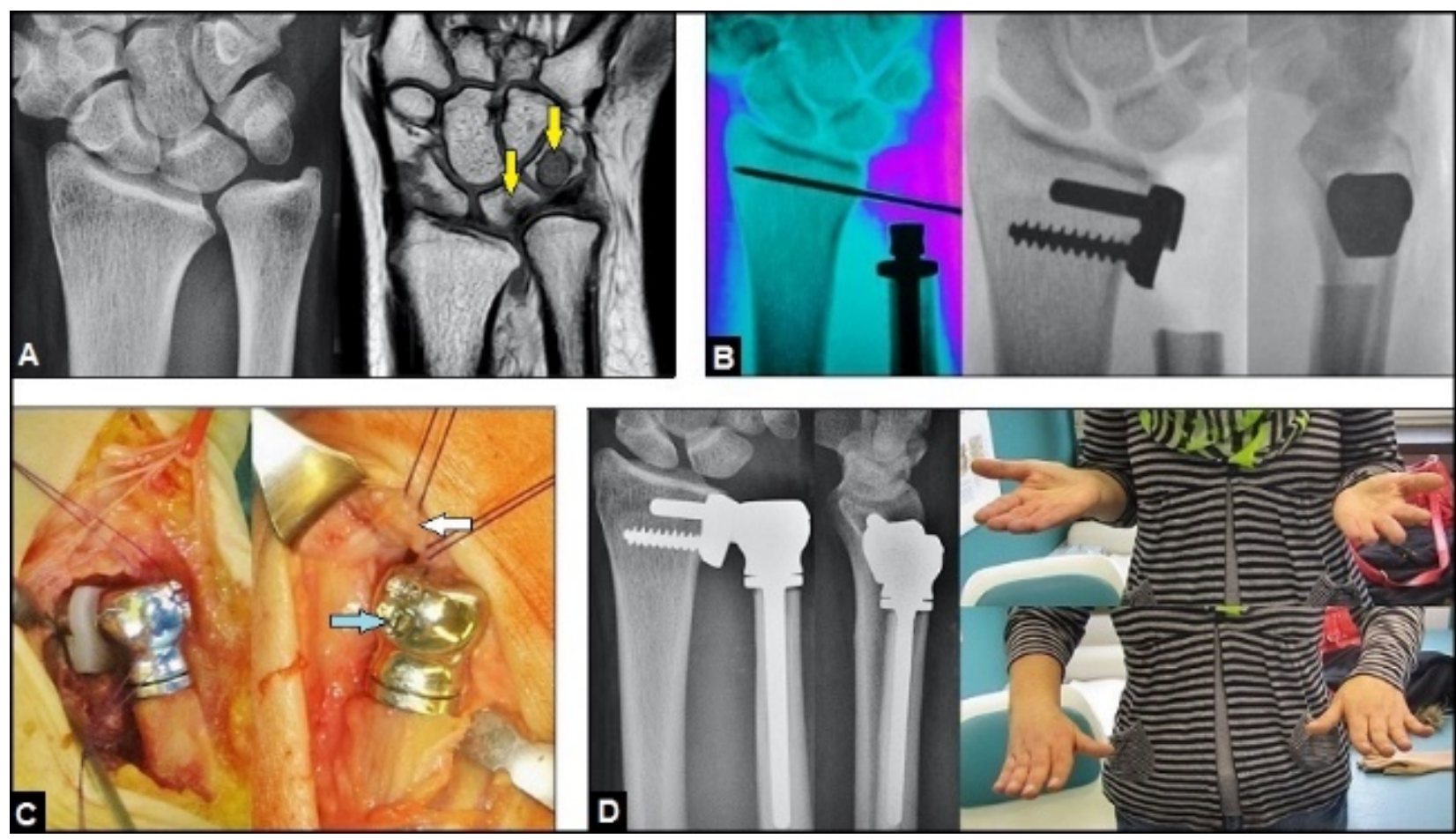

Figure 14 (Example for the necessity of an intact and well functioning ulnar-sided extrinsic extensor mechanism for stability of the distal radioulnar joint when a semiconstrained total joint arthroplasty is required, 54-year-female, right) (A) Initial findings, hereditary ulna positive variance accompanied with a dysplastic sigmoid notch that led to a symptomatic ulnocarpal abutment (arrows). (B) Same patient, correct alignment of the STABILITY ${ }^{\mathrm{TM}}$ Sigmoid Notch (Stryker Corporation, Kalamazoo, Michigan/USA) was assessed intraoperatively by fluoroscopy. (C) Same patient, insertion of the $\mathrm{uHead}^{\mathrm{TM}}$ ulnar head implant (Stryker Corporation, Kalamazoo, Michigan/USA). The tendon sheaths of the extensor carpi ulnaris and extensor digiti minimi (white arrow) which are important stabilizers for the ulnar head will be reattached over the holes of the ulnar head implant (blue arrow) [49-55]. (D) Same patient, excellent functional outcome with a arc of forearm rotation of $170^{\circ}$ and without any signs of static instability 1 year postoperatively. 
Schmidt I (2017) The rare injury of a closed digital extensor tendon avulsion of the third finger at its musculotendinous junction: Case presentation and brief overview of literature with regard to general, specific and practicable aspects to extensor tendon surgery involving tendon transfer procedures

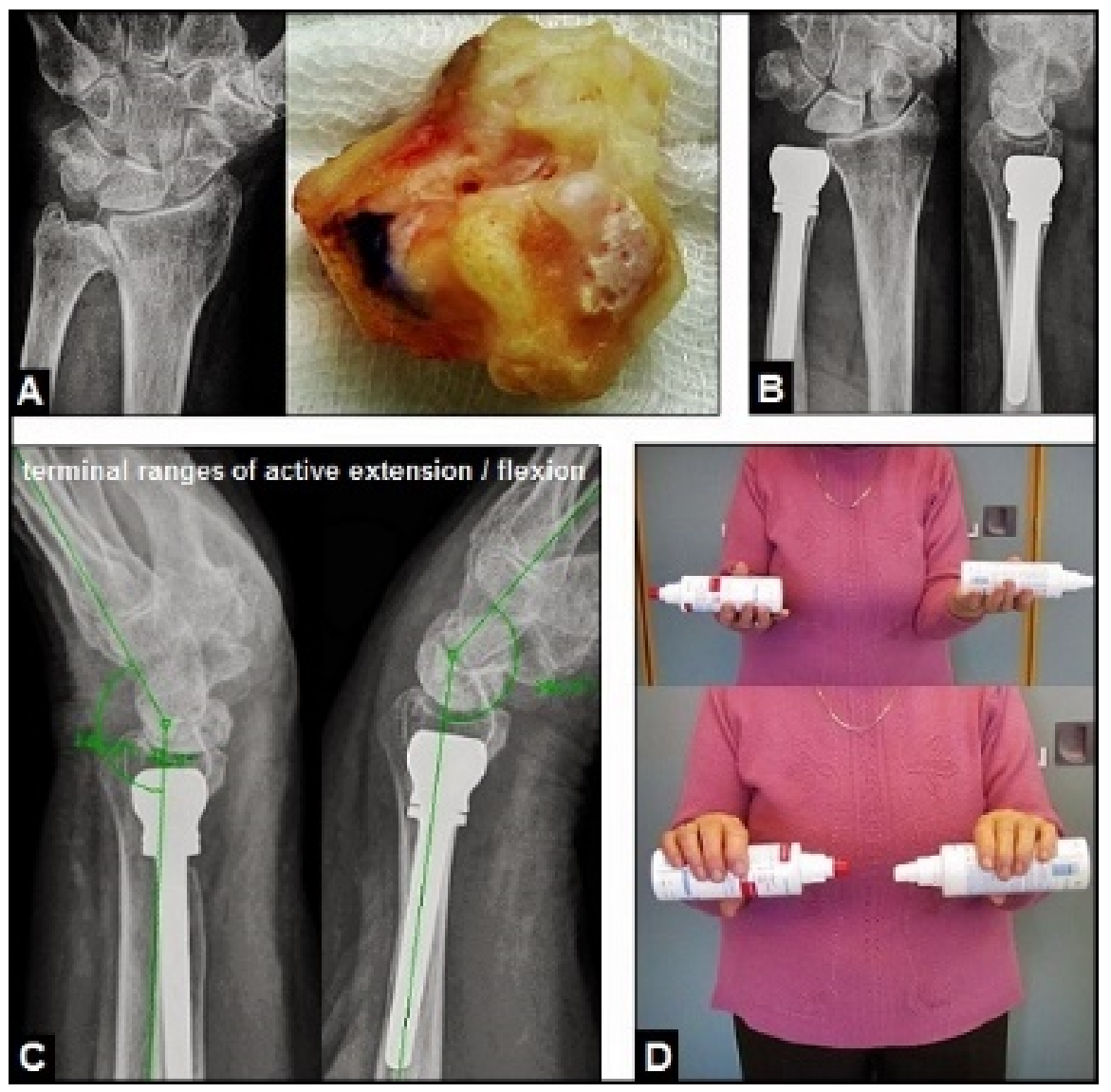

Figure 15 (Example for the necessity of an intact and well functioning ulnar-sided extrinsic extensor mechanism for stability of the distal radioulnar joint when an ulnar head replacement is required, 72-year-old female, left): (A) Initial findings, advanced stage of primary distal radioulnar joint osteoarthritis with marked deformation and arthritic changes of the ulnar head. (B) Same patient, surgical treated by an ulnar head replacement using the uHead ${ }^{\mathrm{TM}}$ implant without any signs of static instability. (C) Same patient, lateral radiographs at terminal ranges of motion 2 years postoperatively did not reveal dynamic instability of the implant. (D) Same patient, excellent functional outcome with a arc of forearm rotation of $180^{\circ} 2$ years postoperatively.
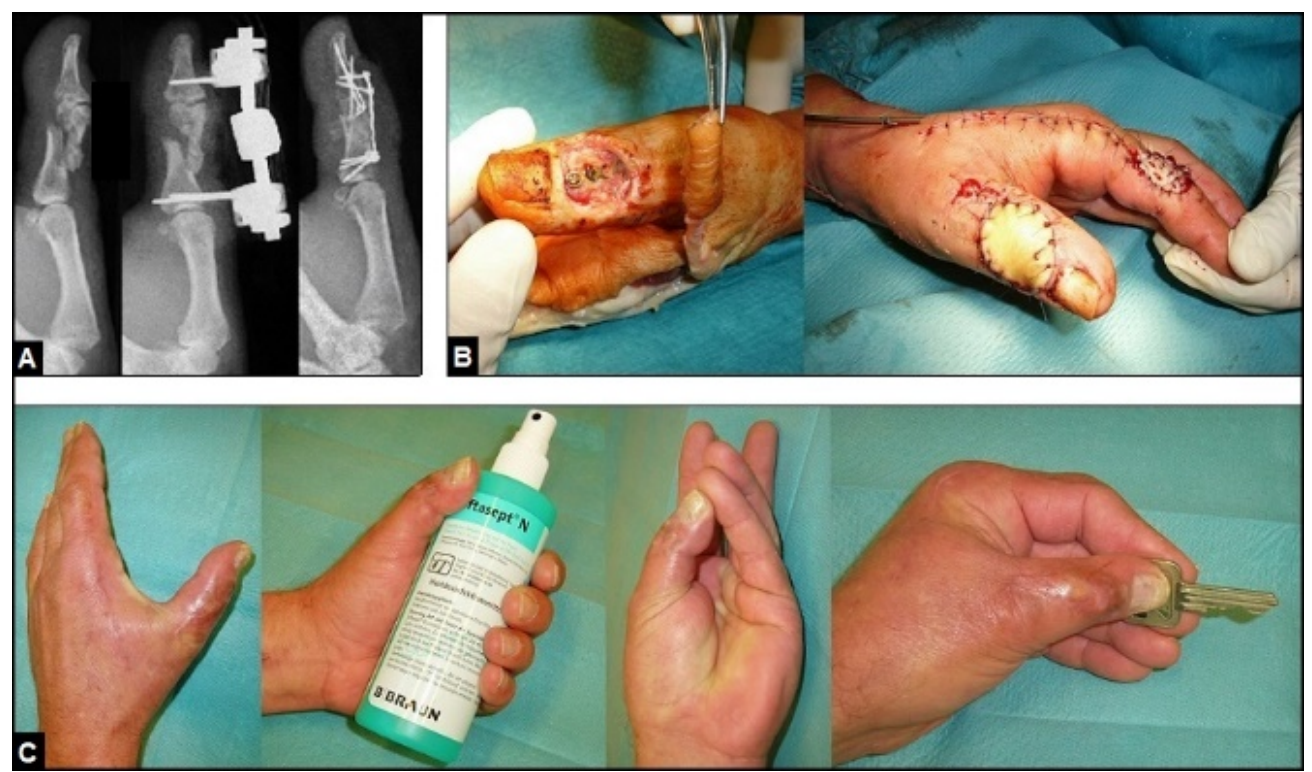

Figure 16 (Example for the necessity of primary finger joint arthrodesis when a tendon repair is not possible, 54-year-old male, left thumb). (A) The patient sustained an occupational crush injury with highly comminuted fracture of the proximal phalanx involving the IPJ accompanied with severe closed soft tissue injury and subcutaneous damage of the distal part of EPL tendon of his left thumb by a blow with a heavy hammer. Initially, the injury was surgical treated by closed reduction and external fixation, and followed by open reduction and internal fixation. A surgical repair of the EPL tendon was technically no longer possible, and so, the arthrodesis of the IPJ had to be performed. (B) Same patient, the further course was complicated by secondary soft tissue necrosis with exposure of the hardware. The soft tissue defect was covered by the first dorsal metacarpal artery skin island flap such as in Figures 10A-D and 12A-E. The flap's donor site was covered primarily by a free skin graft. (C) Same patient, satisfactory outcome 1 year after injury. 
Schmidt I (2017) The rare injury of a closed digital extensor tendon avulsion of the third finger at its musculotendinous junction: Case presentation and brief overview of literature with regard to general, specific and practicable aspects to extensor tendon surgery involving tendon transfer procedures

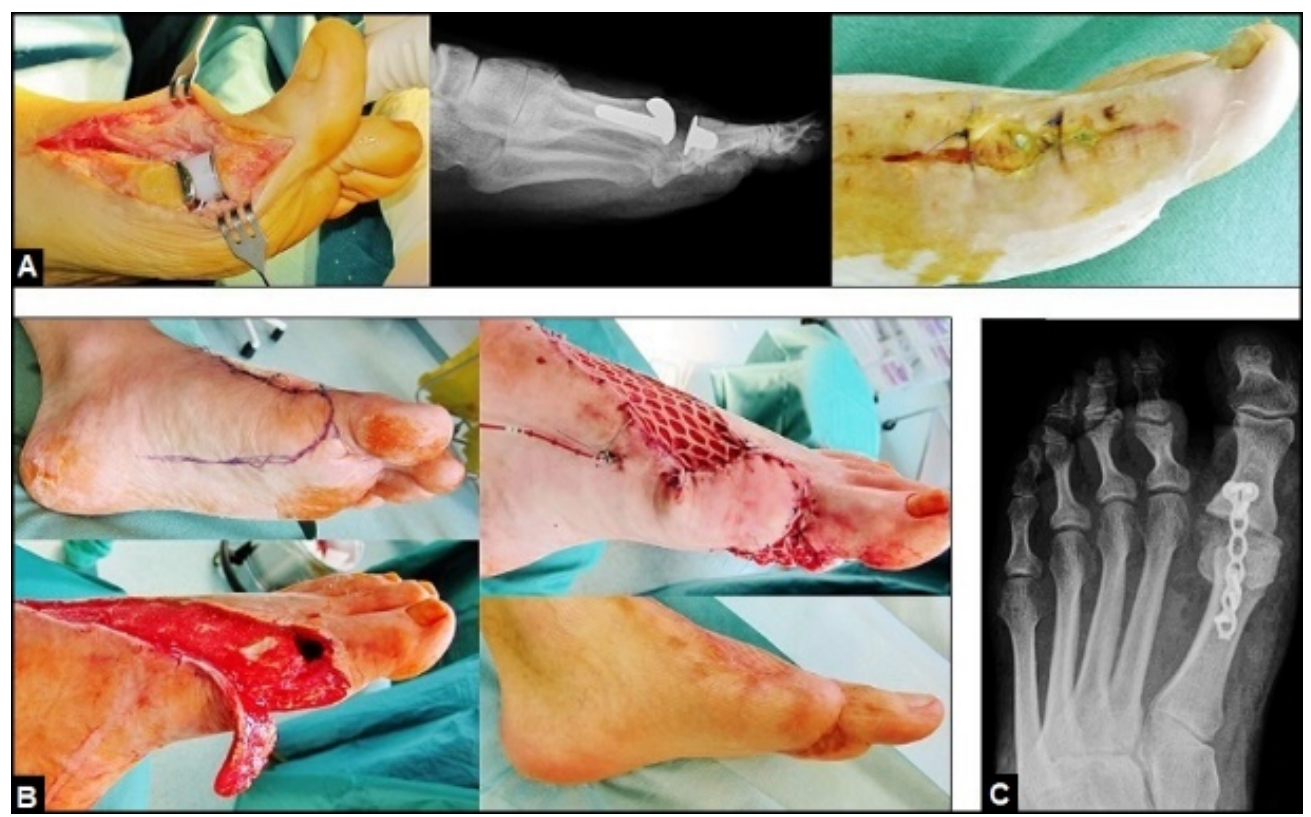

Figure 17 (Example for the necessity of secondary arthrodesis of the metatarsophalangeal joint of the great toe due to an infection after total joint replacement, 37-year-old male, left): (A) This patient sustained a motion-preserving total joint replacement using the ROTO-glide ${ }^{\mathrm{TM}}$ (intercus, Aarau/Switzerland) due to a severe posttraumatic osteoarthritis. The further course was complicated by severe infection with exposure of the implant. (B) Same patient, the infection had to be surgical treated by removal of implant followed by radical debridements involving the extensor hallucis longus tendon, and so, a secondary re-insertion of a motion-preserving implant would not have been successful. Planning and performing the coverage of the resulting soft tissue defect by a proximally pedicled random skin transposition flap, the wound healing was uneventful. The aim of this simple and reliable flap is that it does not require microsurgical expertise [56]. (C) Same patient, the joint arthrodesis was performed after consolidation of soft tissue defect.

Tendon avulsions at its MTJs are rare injuries accounting only $5,1 \%$ of cases in comparison to $62,8 \%$ of cases in which the avulsions take place at its insertion point, and it can be a challenging therapeutic problem because the tendon's vascularity, which is an essential prerequisite for tendon healing, here is generally compromised [4,17,22]. Although uncommon, this injury should not be overlooked. Boyes et al. reported that failure in management could result in unrecognized compartment syndrome in the forearm as well as in the hand [2]. For surgical repair of tendon avulsion at the MTJ, TTPs are the method of choice. TTPs were introduced in the late 19th century independently of one another by Drobnik and Franke to restore functionality in patients with nerve palsies in the hand and foot caused by poliomyelitis, and it has proven to be unchanged a reliable option for other traumatic or non-traumatic conditions [57-61]. A TTP for treatment of peripheral nerve palsy is defined as relocation of the insertion of a functioning (i.e. antagonistic) MTU in order to restore lost movement and function at another site with irreparable nerve palsy or damage. Based on fundamental experiences with a large number of patients who sustained gunshot injuries at the upper extremity during the World Wars I and II, this method was decisively further developed for treatment of peripheral extrinsic-related radial nerve palsy [62-64]. In 1933, Ober was the first who has described the tibialis posterior transfer for functional recovery of foot drop caused by the extrinsic-related common peroneal nerve palsy [65]. For functional recovery of patients with distal intrinsicrelated median and/or ulnar nerve palsies, the EIP transfer (Figures 18A-D) first described by Burkhalter et al. in 1973, and the dynamic or static tenodeses such as the lasso procedure first described by Zancolli in 1979 for correction of claw finger deformities or the rerouting of a split of the flexor digitorum superficialis (FDC) IV to the EDC (Figures 19AB) that creates a viable combination both for correction of the intrinsicrelated claw finger and abduction deformity first described by Stiles in 1922 and later modified by Bunnell, are the most preferred methods, and the Stiles-Bunnell procedure is an option for correction of a claw toe deformity as well [66-77]. However, the use of the FDC IV for tendon transfer, that was also described by Boyes in 1962 and later modified by Chuinard et al. for functional recovery after radial nerve palsy, is not free of any problems such as development of superficialis-minus and subsequent swan neck deformity which must be differentiated from the buttonhole (i.e. Boutonniere) deformity (Figures 20A-B), it is observed in up to $15 \%$ of cases after surgical detachment of the FDS using as donor tendon for a TTP and it requires surgical intervention when the function is impaired [78-81]. Since 1948, the Pulvertaft tendon weaving suture technique which was used in our presented case has been one of the popular methods used in tendon transfers, however, the outcome of a TTP depends on the strength of repair, which allows early active mobilization, and thence better range of motion without risk of rupture [82-84]. A biomechanical study revealed that both the Pulvertaft 3-and 4 -weave repair could allow early and safe active mobilization [85]. The main problem with the Pulvertaft weaving is failure by the suture knots either slipping or pulling through the tendon, and a step-cut side-toside tendon suture is an alternative to reduce bulkiness that is mostly observed with the use of the Pulvertaft weaving [86,87].

In decision making whether a tendon end-to-end repair is still possible or a TTP becomes necessary, the level of tendon injury should be accurately diagnosed before surgery, and ultrasound and/or magnetic resonance imaging are the methods of choice [4]. Melamed et al. reported a case in which a closed intratendinous tendon rupture of the flexor profundus tendon in Verdan's zone III of the index can mimicing avulsion at its MTJ, and an end-to-end repair was possible intraoperatively [88]. When a TTP for recovery after flexor or extensor tendon MTJ avulsions becomes necessary, the use of the EIP, extensor digiti minimi, PL, flexor carpi radialis, extensor carpi radialis, and FDC (i.e. Boyes procedure) either with side-to-side or end-to-side repair is common $[4,5,89]$. Although the EIP is a weak motor, its use for tendon transfer such as in our presented case has proven to be a suitable and reliable option for repair of the ruptured extensor pollicis 
Schmidt I (2017) The rare injury of a closed digital extensor tendon avulsion of the third finger at its musculotendinous junction: Case presentation and brief overview of literature with regard to general, specific and practicable aspects to extensor tendon surgery involving tendon transfer procedures

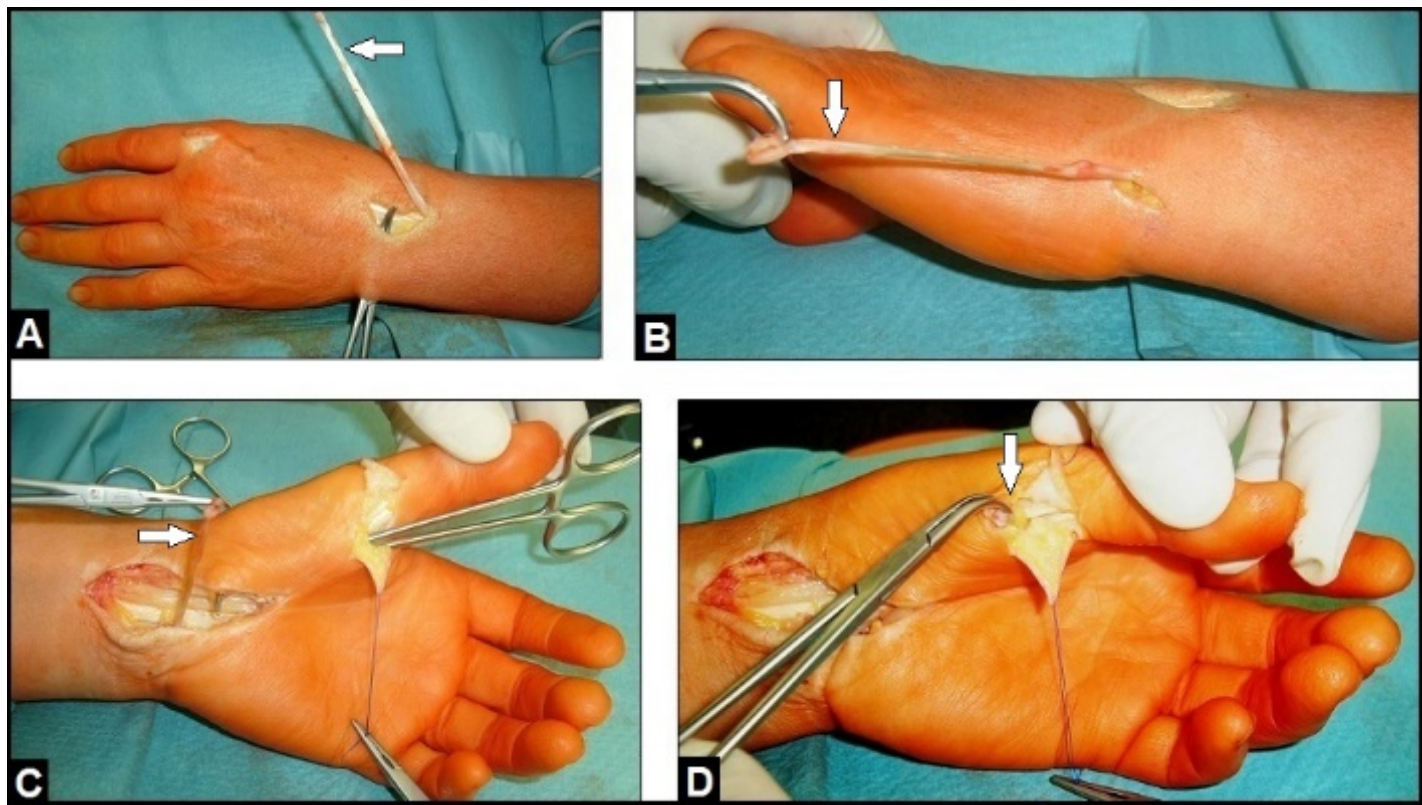

Figure 18 (Example for the Burkhalter TTP in case of an irreparable distal intrinsic-related median nerve paly, 53-year-old female, left): (A) The EIP tendon (arrow) is detached distally. (B) Same patient, the detached EIP tendon is subcutaneous rerouted ulnarwards (arrow). (C) Same patient, subcutaneous rerouting of the EIP tendon palmarwards (arrow). (D) Same patient, subcutaneous translocation of the EIP tendon to the radial sesamoid where its attachment is to be performed (arrow).
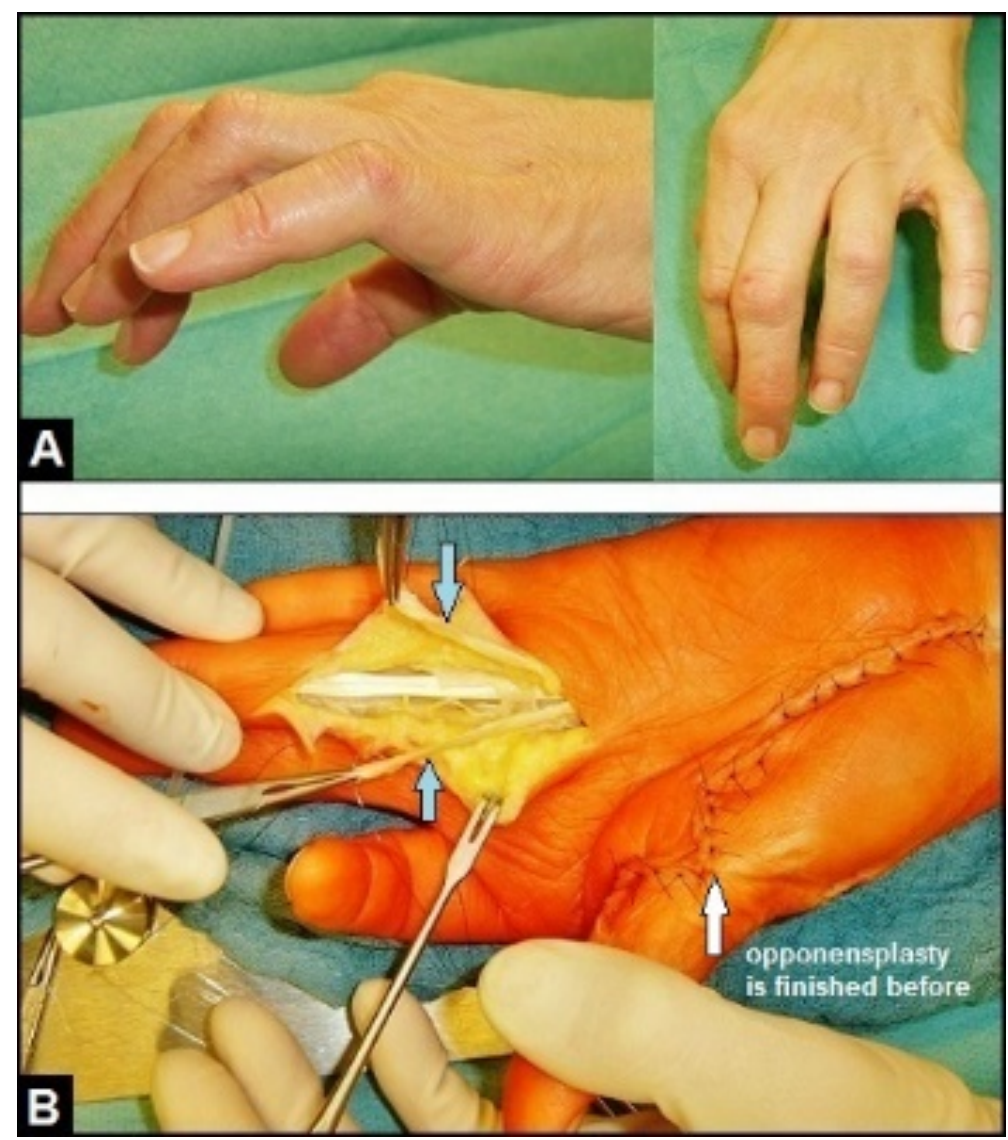

Figure 19 (Example for claw finger correction in case of a combined irreparable distal intrinsic-related median and ulnar nerve palsy, 62-year-old female, left): (A) Initial findings, pronounced claw finger deformities IV/V which present by hyperextension in MCPJ's and flexion in PIPJ's, note the additional abduction deformity of the 5th finger. (B) Same patient, the FDS IV is detached distally and divided longitudinally after its retrograde passing through the A2 pulley (arrows). The radial tendon slip is provided for correction of claw finger IV utilizing the Zancolli lasso procedure (the tendon slip will be retrograde rerouted over the A1 pulley and then sutured with FDS tendon itself). The ulnar tendon slip is provided for correction of claw finger $\mathrm{V}$ accompanied with correction of abduction deformity utilizing the Stiles procedure (the tendon slip will be rerouted dorsally to the EDC tendon of the 5th finger). 


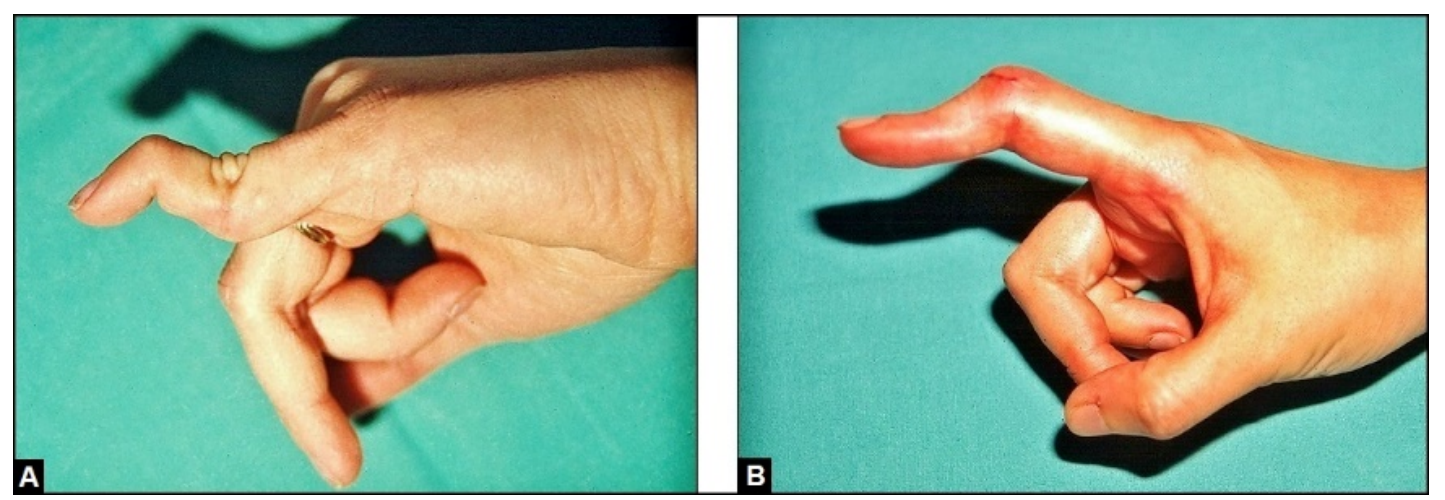

Figure 20 (Examples for swan neck and buttonhole deformity): (A) The swan neck deformity is presented by hyperextension in the PIPJ whereas the DIPJ is fixed in flexed position. This 34-year-old female sustained a closed traumatic avulsion of the FDS V at its distal insertion (base of middle phalanx) many years ago. (B) In contrast, the buttonhole deformity is not caused by an avulsion injury or detachment of the FDS. It is presented by fixed flexion in PIPJ whereas the distal phalanx goes to hyperextension in DIPJ. This 37 -year-old female sustained a closed disruption of the central extensor band at the middle phalanx of the index with subsequent dislocations of the lateral extensor bands palmarwards.

(EPL) tendon, first described in 1925 by Mensch, or distal median nerve palsy (i.e. Burkhalter procedure) [90-94]. However, it must be noted that the EIP has demonstrated variability in its relationship to the EDC II index finger tendon, inserting either palmar or radial to it in $19 \%$ of dissections, supernumerary or bifurcated EIP tendons were found in $13 \%$ of cases, aberrant tendons in $2.8 \%$ of cases, and single EDC index finger tendons has been observed as well [95-97]. For cases in which a EIP tendon with 2 or more small tendon slips are found intraoperatively, the use of the EDC index finger tendon which was found to be the most constant single tendon is recommended for transfer [98]. For tendon repair in case of MTJ avulsions both of the EDC and EIP tendons of the index, the Boyes procedure or transfer of the extensor digiti minimi is described as well $[3,5]$. Tabrizi and Afshar reported on a 42-year-old male sustained a direct blunt trauma to the forearm that led to combined closed extensor tendon ruptures of the index, ring and little finger at its MTJs, end-to-end repairs became not possible due to retraction of the muscles, and so, the injury was repaired by transfer of the extensor carpi radialis longus [99].

To assess the outcome of the EIP tendon transfer, 3 features are to be considered: first, does the detachment of the EIP lead to an extension lag and impaired extension strength in MCPJ II; second, does the EIP tendon transfer result in complete functional recovery without strength deficits at the recipient site; and third, are the patients sustaining an EIP tendon transfer able to move their fingers both at the donor and recipient site separately. To first: detachment of the EIP tendon leads to an extension lag in MCPJ II ranging from 0 to $25^{\circ}$ and decreased extension strength ranging from 35 to $50 \%$ compared to the opposite index, but it is almost always well tolerated by the patients performing their activities of daily living at averaged follow-up's ranging from 12 months up to 15 years $[91,92,94,98,100]$. To second: reliable data could only found by the authors in 2 studies for the EIP tendon transfer to the EPL tendon. The persistent extension lag in IPJ of the thumb is reported to be up to $35^{\circ}$ associated with an strength deficit up to $49 \%$ to the opposite thumb, but it is almost always well tolerated by the patients performing their activities of daily living as well at averaged followup's ranging from 26 months to 5.3 years $[91,92]$. To third: There are serious differences in the literature between the reported outcomes in patients sustained the EIP tendon transfer to the traumatic ruptured EPL and patients sustained the Burkhalter procedure based on distal median nerve palsy. With a total number of 35 EIP to EPL TTPs out of 2 studies, all patients were able to extend their fingers separately at averaged follow-up's ranging from 26 months to 5.3 years [91,92].
Martinez-Martinez et al. reported on 2 patients who sustained closed MTJ avulsions of both the EDCII and EIP tendons due to indirect minor traumata and treated surgically by transfer of the FDS IV through the interosseous membrane to the EIP (i.e. Boyes procedure), both patients were able to perform independent extension of their index fingers ( 1 patient with an extension lag in MCPJ II of $5^{\circ}$ only) 3 months after surgery [5]. Komura et al. reported on 2 patients who sustained MTJ avulsions of both the EDCII and EIP tendons as well (with both patients their work gloves became in machines), the first patient was treated surgically by end-to-side suture of the distal stump of EDC II at the EDC III and he was unable to extend his index finger independently in typing keyboard and pushing a button 6 months after surgery whereas the second patient was surgically treated by transfer of the extensor digiti minimi and he was completely able to perform independent extension of his index finger 3 months after surgery [3]. In contrast, none of 15 patients with traumatic distal median nerve palsies sustained the Burkhalter procedure were able to perform independent extension in their index fingers at a follow-up described as "over the past 15 years" [94]. Also in contrast with regard to TTPs in patients with radial nerve palsies, there was observed in short- to long-term follow-up's that the ability to simultaneously extend the wrist and long fingers II-V cannot be achieved in most of patients treated by triple transfer procedures, whereas the majority of patients are able to move their long fingers separately $[101,102]$. The causes for this specific feature are still widely unknown, but probably based on cortical changes that has been investigated in number of settings such for finger amputation, thumb reconstruction with toe-to-toe transfer, dynamic immobilization, required trauma- and sarcoma-related amputations of the upper extremity and phantom limb pain with or without a hand prosthesis, macroreplantation at the upper extremity, but not for TTPs [103-108]. Interestingly, Bezuhly et al. reported that all of 7 patients sustained an EIP to EPL tendon transfer under the condition of the wide-awake approach with pure local anesthesia of lidocaine with 1:200,000 epinephrine and no tourniquet were able to independently extend the thumb and index finger on the first attempt in the operation room without having to practice the movement, and a concomitant flicker of flexion was noted in the neighboring index finger with the first attempt at thumb extension [109]. Also, each of these 7 patients answered to the question what they were thinking when they used the TTP the first time that they were trying to lift their thumb but not their index finger. These observations would appear that the brain is able to learn this new function instantly rather than after months of intensive hand therapy, as is commonly thought for tendon transfer [109]. 
Schmidt I (2017) The rare injury of a closed digital extensor tendon avulsion of the third finger at its musculotendinous junction: Case presentation and brief overview of literature with regard to general, specific and practicable aspects to extensor tendon surgery involving tendon transfer procedures

\section{Declarations}

The authors declare that they have none conflict of interests concerning this article.

\section{Acknowledgements}

The corresponding author would like to thank Univ. Prof. em. Dr. med. habil. Abdul-Kader Martini (Heidelberg/Germany, President of the German Society for Hand Surgery (DGH) from 2006 to 2008, Honourary Member of the DGH) for his excellent scientific support over the past years, and especially for the possibility to cooperate with him as referent and instructor to the anatomical hand and wrist courses at the Anatomical Institute of the University of Heidelberg in 2010, 2011 and 2012 as well as to the hand and wrist satellite workshops to the Annual Meetings of the DGH in 2011 (Bonn/Germany) and 2012 (Lübeck/Germany) under his respective scientific leaderships.

\section{References}

1. Bruner JM (1973) Surgical exposure of flexor tendons in the hand. Ann R Coll Surg Engl 53: 84-94. [Crossref]

2. Boyes JH, Wilson JN, Smith JW (1960) Flexor-tendon ruptures in the forearm and hand. J Bone Joint Surg Am 42-42A: 637-46. [Crossref]

3. Komura S, Yokoi T, Nonomura H (2011) Traumatic closed index extensor tendon rupture at the musclotendinous junction: a report of two cases. Hand (NY) 6: 90-92.

4. Collins J, Ishihara Y, Thoma A (2012) Management of digital tendon avulsion at the musculotendinous junction of the forearm: a systematic review. Hand (NY) 7: 134-142.

5. Martinez-Martinez F, Moreno-Fernandez JM, Rotella PS, Santonja-Medina F, MedinaQuiros M, Garcia-Lopez A (2015) Spontaneous rupture of extensor tendons of the index finger. A report of two cases. Hand (NY) 10: 570-573.

6. Sasi PK, Mahapatra S, Raj Pallapati SC, Thomas BP (2016) Acute Traumatic Musculotendinous Avulsion of the Flexor Pollicis Longus Tendon Treated with Primary Flexor Digitorum Superficialis Transfer: A Novel Technique of Management. Case Rep Orthop 2016: 2106203. Epub 2016 Feb 25.

7. McMaster PE (1933) Tendon and muscle ruptures: Clinical and experimental studies on the causes and location of subcutaneous ruptures. J Bone Joint Surg Am 15: 705-722.

8. Schmidt I (2017) A 10-Year Follow-Up of Uncemented Constrained Metacarpophalangeal Joint Arthroplasties Using the RM Prosthesis in a Patient with Rheumatoid Arthritis. J Rheumatol Arthritic Dis 2: 1-5.

9. Schmidt I (2017) The idiopathic avascular osteonecrosis of the 3rd metacarpal head (M. Mauclaire / Dieterich's disease). Int J Case Rep Images 8: 92-95.

10. Tomaino MM, Leit M (2006) Finger metacarpophalangeal joint disease: the role of resection arthroplasty and arthrodesis. Hand Clin 22: 195-200.

11. Rongières M (2013) Surgical treatment of degenerative osteoarthritis of the fingers. Chir Main 32: 193-198. [Crossref]

12. Schmidt I (2017) Posttraumatic ulnar carpal translocation type I accompanied with disruption of the lunotriquetral ligament caused by a severe radiocarpal fracturedislocation injury type II accompanied with complete luxation of the distal radioulnar joint. What are the salvage options with its special features in indication when patients develop posttraumatic painful wrist joint osteoarthritis? Trauma Emerg Care 2: doi: 10.15761/TEC.1000138

13. Markgraf E, Schmidt I, Friedel R, Dönicke T (1996) The pathophysiology of wound healing processes - Overview. OP-JOURNAL (Thieme, Stuttgart - New York) 12: 4-9.

14. Friedel R, Schmidt I (1997) [The treatment concept in severe hand injuries]. Zentralbl Chir 122: 1016-1023. [Crossref]

15. Dorow C, Markgraf E (1997) [Therapy of soft tissue injuries--biological strategies]. Zentralbl Chir 122: 962-969. [Crossref]

16. Schmidt I, Friedel R, Schmitz H, Marx F, Markgraf E (2000) The Marjolin's ulcer": a malignant and rarely complication after burn trauma of the upper extremity - a case report. Unfallchirurg 103: 68-72. [Crossref]

17. Sharma P, Maffulli N (2006) Biology of tendon injury: healing, modeling and remodeling. J Musculoskelet Neuronal Interact 6: 181-190. [Crossref]

18. Malahias M, Jordan D, Hughes O, Khan WS, Hindocha S (2014) Bite injuries to the hand: microbiology, virology and management. Open Orthop J 8: 157-161. [Crossref]

19. Rigo IZ, Røkkum M (2016) Predictors of outcome after primary flexor tendon repair in zone 1, 2 and 3. J Hand Surg Eur Vol 41: 793-801. [Crossref]

20. Schmidt I (2017): The distally pedicled peroneus brevis muscle and fasciocutaneous sural artery flap for reconstruction of the distal third of lower leg. Int J Case Rep Images 8: 17-21.

21. Sameem M, Wood T, Ignacy T, Thoma A, Strumas N (2011) A systematic review of rehabilitation protocols after surgical repair of the extensor tendons in zones V-VIII of the hand. J Hand Ther 24: 365-372.

22. Singh R, Rymer B, Theobald P, Thomas PB (2015) A Review of Current Concepts in Flexor Tendon Repair: Physiology, Biomechanics, Surgical Technique and Rehabilitation. Orthop Rev (Pavia) 7: 6125.

23. Tang JB, Zhou X, Pan ZJ, Qing J, Gong KT, et al. (2017) Strong Digital Flexor Tendon Repair, Extension-Flexion Test, and Early Active Flexion: Experience in 300 Tendons. Hand Clin 33: 455-463.

24. Pan ZJ, Qin J, Zhou X, Chen J (2017) Robust thumb flexor tendon repairs with a sixstrand M-Tang method, pulley venting, and early active motion. J Hand Surg Eur Vol doi: $10.1177 / 1753193417723238$. [Epub ahead of print]

25. Schmidt I (1996) Strategy and management of complex injuries of the hand Unfallmedizinische Tagung des Landesverbandes Hessen-Mittelrhein und Thüringen der gewerblichen Berufsgenossenschaften (9./10. November in Mainz) 96: 208-221.

26. Schmidt I (2017) A 20-year follow-up after replantation of the right midfoot in an eight-year-old child. In J Case Rep Images 8: 293-295.

27. Chamay A (1988) A distally based dorsal and triangular tendinous flap for direct access to the proximal interphalangeal joint. Ann Chir Main 7: 179-183.

28. Yang GF, Chen B, Gao Y (1981) Forearm free skin flap transplantation. Natl Med J China 61: 139-142.

29. Stock W, Mühlhauer W, Biemer E (1981) The neurovascular forearm island flap. $Z$ Plast Chir 5: 158-165. [Crossref]

30. Lu KH (1982) The forearm radial arterial turnover flap and its clinical applications. Zhonghua Wai Ke Za Zhi 20: 695-697, 704. [Crossref]

31. Piza-Katzer H, Weinstabl R, Firbas W (1988) The venous blood-flow of the flexor aspect of the human forearm. Clinical relevance to the distally-pedicled forearm flap. Surg Radiol Anat 10: 229-232.

32. Karacalar A, Idil O, Ozcan M (1998) Simultaneous soft-tissue reconstruction and revascularization of the thumb with a flow-through distally pedicled radial forearm flap. J Reconstr Microsurg 14: 449-452.

33. Hilgenfeldt O (1950) Operativer Daumenersatz und Beseitigung von Greifstörungen bei Fingerverlusten. Enke, Stuttgart.

34. Foucher G, Braun JB (1979) A new island flap transfer from the dorsum of the index to the thumb. Plast Reconstr Surg 63: 344-349. [Crossref]

35. Littler JW (1953) The neurovascular pedicle method of digital transposition for reconstruction of the thumb. Plast Reconstr Surg (1946) 12: 303-319. [Crossref]

36. Simmons BP, Vasile RG (1980) The clenched fist syndrome. J Hand Surg Am 5: 420427. [Crossref]

37. Ryzewicz M, Wolf JM (2006) Trigger digits: principles, management, and complications. J Hand Surg Am 31: 135-146. [Crossref]

38. Zeineh LL, Wilhelmi BJ, Seidenstricker L (2008) The clenched fist syndrome revisited. Plast Reconstr Surg 121: 149e-150e. [Crossref]

39. Weis T, Boeckstyns ME (2009) The clenched fist syndrome: a presentation of eigh cases and an analysis of the medicolegal aspects in Denmark. J Hand Surg Eur Vol 34: 374-378. [Crossref]

40. Langer M, Lötters E, Wieskötter B, Surke C (2011) Hand und psychische Erkrankungen. In: Towfigh H, Hierner R, Langer M, Friedel R (eds.), Handchirurgie (Springer, BerlinHeidelbderg): 1786-1793.

41. Basaran K, Datli A, Kurt M (2014) An important diagnosis for the hand surgeon: "the clenched fist syndrome". J Plast Reconstr Aesthet Surg 67: 1304-1306. [Crossref]

42. Helm R (2010) Bilateral hand amputation due to clenched fist syndrome. J Hand Surg Eur Vol 35: 249. [Crossref] 
Schmidt I (2017) The rare injury of a closed digital extensor tendon avulsion of the third finger at its musculotendinous junction: Case presentation and brief overview of literature with regard to general, specific and practicable aspects to extensor tendon surgery involving tendon transfer procedures

43. Langer MF, Oeckenpöhler S, Hartensuer R, Herrmann K, Wieskötter B (2015) Pulley reconstruction in the hand. Orthopade 44: 757-766. [Crossref]

44. Hamada Y, Sairyo K, Hibino N, Kobayashi A (2015) Correction of Severe Contracture of Intrinsic Plus Hand with a Modified Ilizarov Mini-Fixator: Correction with an Ilizarov Mini-Fixator for Severe Hand Contracture. J Hand Microsurg 7: 161-165.

45. Schöffl V, Popp D, Küpper T, Schöffl I (2015) Injury trends in rock climbers: evaluation of a case series of 911 injuries between 2009 and 2012. Wilderness Environ Med 26: 62-67. [Crossref]

46. Prommersberger KJ, Mühldorfer-Fodor M, Kalb K (2015) [Hand injuries in mountain sports]. Unfallchirurg 118: 515-519. [Crossref]

47. Halim A, Weiss AC (2017) Total Wrist Arthroplasty. J Hand Surg Am 42: 198-209. [Crossref]

48. Schmidt I (2015) Can Total Wrist Arthroplasty Be an Option for Treatment of Highly Comminuted Distal Radius Fracture in Selected Patients? Preliminary Experience with Two Cases. Case Rep Orthop 2015:380935. doi: 10.1155/2015/380935. Epub 2015 Sep 29 .

49. Berger RA (2008) Indications for ulnar head replacement. Am J Orthop (Belle Mead NJ) 37: 17-20. [Crossref]

50. Ewald TJ, Skeete K, Moran SL (2012) Preliminary experience with a new total distal radioulnar joint replacement. $J$ Wrist Surg 1: 23-30. [Crossref]

51. Berger RA (2013) Implant arthroplasty for treatment of ulnar head resection-related instability. Hand Clin 29: 103-111. [Crossref]

52. Schmidt I (2014) Primary combined replacements for treatment of distal radius physeal arrest. J Wrist Surg 3: 203-205. [Crossref]

53. Schmidt I (2015) Combined replacements using the Maestro total wrist and uHead ulnar head implants. J Hand Surg Eur Vol 40: 754-755. [Crossref]

54. Schmidt I (2017) RE-MOTION ${ }^{\mathrm{TM}}$ total wrist arthroplasty for treatment of advanced stage of scaphoid non-union advanced collapse. Does excision of the entire scaphoid bone prevent impingement at terminal range of radial deviation? Trauma Emerg Care 2: doi: 10.15761/TEC.1000127.

55. Schmidt I (2017): Combined replacements of the wrist, ulnar head, and thumb carpometacarpal joint. Case report, technical note and recent evidence to the Arpe $\mathrm{T}^{\mathrm{TM}}$ prosthesis. Trauma Emerg Care 2: doi: 10.15761/TEC.1000130.

56. Schmidt I (2016) A large proximally pedicled random skin transposition flap for reconstruction of a critically compromised lower extremity. Int $J$ Case Rep Images 7: $685-686$.

57. Drobnik T (1894) Dalsze doswiadczenia nad leczeniem porazen dzieciecych za pomoca przeniesienia czynnosci miesni. Further experiments on the treatment of the children palsy with using muscles transfer. Nowiny Lekarsky 323.

58. Pietrzak K, Grzybowski A, Kaczmarczyk J (2014) Tomasz Drobnik (1858-1901)--an assistant who equalled his masters. World J Surg 38: 1238-1242. [Crossref]

59. Franke F (1899) Über die operative Behandlung der Radialislähmung nebst Bemerkungen über die Sehnenüberpflanzungen bei spastischen Paresen. Arch Klin Chir 57: 763 .

60. Schmidt I (2017) Irreparable Radial Nerve Palsy Due to Delayed Diagnostic Management of a Giant Lipoma at the Proximal Forearm Resulting in a Triple Tendon Transfer Procedure: Case report and Brief Review of Literature. Open Orthop J 11: 794-803.

61. Schmidt I (2017) Common peroneal nerve palsy caused by an initially misdiagnosed extra- and intraneural ganglion cyst of the peroneal nerve in a 11-year old child - A rare but severe condition. Int J Case Rep Images 8: 623 - 626.

62. Jones R (1916) II. On suture of nerves, and alternative methods of treatment by transplantation of tendon. $\mathrm{Br}$ Med J 1: 641-643. [Crossref]

63. d'Aubigné RM, Lance P (1946) Tendon transplantation in treatment of post traumatic radial paralysis. Sem Hop 22: 1666-1667.

64. Zachary RB (1946) Tendon Transplantation for Radial Paralysis. Proc R Soc Med 39: 722. [Crossref]

65. Ober FR (1933) Tendon transplantation in the lower extremity. $N$ Engl J Med 209: 52-59.

66. Burkhalter W, Christensen RC, Brown P (1973) Extensor indicis proprius opponensplasty. J Bone Joint Surg Am 55: 725-732. [Crossref]
67. Zancolli E (1979) Intrinsic paralysis of the ulnar nerve--physiopatholgy of the claw hand. In: Zancolli E(ed.) Structural and dynamic bases of hand surgery. Lippincott, Philadelphia (2nd edn.): 159-206.

68. Brand PW (1958) Paralytic claw hand; with special reference to paralysis in leprosy and treatment by the sublimis transfer of Stiles and Bunnell. J Bone Joint Surg Br 4040B: 618-32. [Crossref]

69. Valero-Cuevas FJ, Hentz VR (2002) Releasing the A3 pulley and leaving flexo superficialis intact increases pinch force following the Zancolli lasso procedures to prevent claw deformity in the intrinsic palsied finger. J Orthop Res 20: 902-909.

70. Ozkan T, Ozer K, Yukse A, Gulgonen A (2003) Surgical reconstruction of irreversible ulnar nerve paralysis in leprosy. Lepr Rev 74: 53-62. [Crossref]

71. Jones NF, Machado GR (2011) Tendon transfers for radial, median, and ulnar nerve injuries: current surgical techniques. Clin Plast Surg 38: 621-642.

72. Martini AK (2013) Motorische Ersatzoperationen. In: Martini AK (ed.) Orthopädische Handchirurgie. Manual für Klinik und Praxis. Springer, Heidelberg: 175-188.

73. Akram M, Farooqi FM, Shahzad ML, Irshad M, Sah RK, Awais SM (2014) Burkhalter opponensplasty; role in isolated median nerve injury. J Pak Med Assoc 64: S172-174.

74. Pillukat T, Ritter S, Fuhrmann RA, Windolf J, van Schoonhoven J (2013) Operative treatment of claw deformity by lassoplasty. Oper Orthop Traumatol 25: 331-339. [Crossref]

75. Gupta V, Consul A, Swamy MK (2015) Zancolli lasso procedure for correction of paralytic claw hands. J Orthop Surg (Hong Kong) 23: 15-18. [Crossref]

76. Muradian AA (2016) Zancolli Lasso Tendon Transfer For Ulnar Claw Hand; A Short Term Outcome Analysis Of Sixteen Cases. Base J Surg 22: 80-86.

77. Lin YT, Loh CYY, Lien SH, Lin CH, Wei FC (2017) Simultaneous Stiles-Bunnell Tendon Transfer Enhances Intrinsic Function of the Second Toe Transplantations. Plast Reconstr Surg Aug 8. doi. 10.1097/PRS.0000000000003861. [Epub ahead of print]

78. Boyes JH (1962) Selection of a donor muscle for tendon transfer. Bull Hosp Joint Dis 23: 1-4. [Crossref]

79. Chuinard RG, Boyes JH, Stark HH, Ashworth CR (1978) Tendon transfers for radia nerve palsy: use of superficialis tendons for digital extension. J Hand Surg Am 3: 560570. [Crossref]

80. Brandsma JW, Ottenhoff-De Jonge MW (1992) Flexor digitorum superficialis tendon transfer for intrinsic replacement. Long-term results and the effect on donor fingers. $J$ Hand Surg Am 17: 635-628.

81. Charruau B, Laulan J, Saint-Cast Y (2016) Lateral band translocation for swan-neck deformity: Outcomes of 41 digits after a mean follow-up of eight years. Orthop Traumatol Surg Res 102(Suppl.): S221-224.

82. Pulvertaft RG (1948) Repair of tendon injuries in the hand. Ann R Coll Surg Engl 3 : 3-14. [Crossref]

83. Pulvertaft RG (1956) Tendon grafts for flexor tendon injuries in the fingers and thumb; a study of technique and results. J Bone Joint Surg Br 38-38B: 175-94. [Crossref]

84. Bidic SM, Varshney A, Ruff MD, Orenstein HH (2009) Biomechanical comparison of lasso, Pulvertaft weave, and side-by-side tendon repairs. Plast Reconstr Surg 124 $567-571$

85. Yuen CP, Yen CH, Leung HB, Tse WL, Ho PC, Hung LK (2011) In vitro Biomechanica Study of Pulvertaft Tendon Weaving Technique. J Orthop Trauma Rehabil 15: 62-64.

86. Brown SH, Hentzen ER, Kwan A, Ward SR, Fridén J, et al. (2010) Mechanical strength of the side-to-side versus Pulvertaft weave tendon repair. J Hand Surg Am 35: 540-545. [Crossref]

87. Hashimoto T, Thoreson AR, An KN, Amadio PC, Zhao C (2012) Comparison of stepcut and Pulvertaft attachment for flexor tendon graft: a biomechanics evaluation in an in vitro canine model. J Hand Surg Eur Vol 37: 848-854.

88. Melamed E, Fineberg SJ, Beldner S (2015) Closed Rupture of the Flexor Profundus Tendon of Ring Finger: Case Report and Treatment Recommendations. Am J Orthop (Belle Mead NJ) 44: 373-375.

89. Sasi PK, Mahapatra S, Raj Pallapati SC, Thomas BP (2016) Acute Traumatic Musculotendinous Avulsion of the Flexor Pollicis Longus Tendon Treated with Primary Flexor Digitorum Superficialis Transfer: A Novel Technique of Management Case Rep Orthop doi: 10.1155/2016/2106203. Epub 2016 Feb 25. 
Schmidt I (2017) The rare injury of a closed digital extensor tendon avulsion of the third finger at its musculotendinous junction: Case presentation and brief overview of literature with regard to general, specific and practicable aspects to extensor tendon surgery involving tendon transfer procedures

90. Mensch (1925) Spätruptur der Sehne des Extensor Pollicis Longus. Münch Med Wochenschr 72: 836

91. Magnussen PA, Harvey FJ, Tonkin MA (1990) Extensor indicis proprius transfer for rupture of the extensor pollicis longus tendon. J Bone Joint Surg Br 72: 881-883. [Crossref]

92. De Smet L, Van Loon J, Fabry G (1997) Extensor indicis proprius to extensor pollicis longus transfer: results and complications. Acta Orthop Belg 63: 178-181. [Crossref]

93. Sammer DM, Chung KC (2009) Tendon transfers: Part II. Transfers for ulnar nerve palsy and median nerve palsy. Plast Reconstr Surg 124: 212e-21e. [Crossref]

94. Al-Quattan MM (2012) Extensor indicis proprius opponensplasty for isolated traumatic low median nerve palsy: A case series. Can J Plast Surg 20: 255-257.

95. von Schroeder HP1, Botte MJ (1995) Anatomy of the extensor tendons of the fingers: variations and multiplicity. J Hand Surg Am 20: 27-34. [Crossref]

96. Gonzalez MH, Weinzweig N, Kay T, Grindel S (1996) Anatomy of the extensor tendons to the index finger. J Hand Surg Am 21: 988-991. [Crossref]

97. Komiyama M, Nwe TM, Toyota N, Shimada Y (1999) Variations of the extensor indicis muscle and tendon. J Hand Surg Br 24: 575-578. [Crossref]

98. Meads BM, Bogoch ER (2004) Transfer of either index finger extensor tendon to the extensor pollicis longus tendon. Can J Plast Surg 12: 31-34.

99. Tabrizi A, Afshar A (2016) Closed Extensor Digitorum Communis Tendons Rupture at the Musculotendinous Junction: A Case Report. J Hand Microsurg 8: 120-121.

100. Lemonas P, Laing T, Ghorbanian S, Malahias M, Ragoowansi R (2012) Extensor indicis proprius opponensplasty - the burkhalter revisited. J Hand Microsurg 4: 4749. [Crossref]
101. Kruft S, von Heimburg D, Reill P (1997) Treatment of irreversible lesion of the radial nerve by tendon transfer: Indication and long-term results of the Merle d'Aubigné procedure. Plast Reconstr Surg 100: 610-616.

102. Moussavi AA, Saied A, Karbalaeikhani A (2011) Outcome of tendon transfer for radial nerve paralysis: Comparison of three methods. Indian J Orthop 45: 558-562.

103. Weiss T, Miltner WH, Huonker R, Friedel R, Schmidt I, Taub E (2000) Rapid functional plasticity of the somatosensory cortex after finger amputation. Exp Brain Res 134: 199-203.

104. Manduch M, Bezuhly M, Anastakis DJ, Crawley AP, Mikulis DJ (2002) Serial fMRI of adaptive changes in primary sensorimotor cortex following thumb reconstruction. Neurology 59: 1278-1281.

105. de Jong BM, Coert JH, Stenekes MW, Leenders KL, Paans AM, et al. (2003) Cerebral reorganisation of human hand movement following dynamic immobilisation. Neuroreport 14: 1693-1696.

106. Preissler S, Feiler J, Dietrich C, Hofmann GO, Miltner WH, et al. (2013) Gray matter changes following limb amputation with high and low intensities of phantom limb pain. Cereb Cortex 23: 1038-1048. [Crossref]

107. Preißler S, Dietrich C, Blume KR, Hofmann GO, Miltner WH, et al. (2013) Plasticity in the Visual System is Associated with Prosthesis Use in Phantom Limb Pain. Front Hum Neurosci 7: 311. [Crossref]

108. Blume KR, Dietrich C, Huonker R, Götz T, Sens E, et al. (2014) Cortical reorganization after macroreplantation at the upper extremity: a magnetoencephalographic study. Brain 137: 757-769.

109. Bezuhly M, Sparkes GL, Higgins A, Neumeister MW, Lalonde DH (2007) Immediate thumb extension following extensor indicis proprius-to-extensor pollicis longus tendon transfer using the wide-awake approach. Plast Reconstr Surg 119: 1507-1512.

Copyright: (C2017 Schmidt I. This is an open-access article distributed under the terms of the Creative Commons Attribution License, which permits unrestricted use, distribution, and reproduction in any medium, provided the original author and source are credited. 